\title{
Poly-glycine-alanine exacerbates C9orf72 repeat expansion-mediated DNA damage via sequestration of phosphorylated ATM and loss of nuclear hnRNPA3
}

\author{
Yoshihiro Nihei ${ }^{1} \cdot$ Kohji Mori $^{2} \cdot$ Georg Werner ${ }^{3}$. Thomas Arzberger ${ }^{1,4,5}$. Qihui Zhou ${ }^{1}$. Barham Khosravi ${ }^{1}$. \\ Julia Japtok $^{6} \cdot$ Andreas Hermann $^{7,8} \cdot$ Andreas Sommacal $^{9} \cdot$ Markus Weber $^{10} \cdot$ German Consortium for $^{3}$ \\ Frontotemporal Lobar Degeneration - Bavarian Brain Banking Alliance · Frits Kamp ${ }^{3}$ - Brigitte Nuscher ${ }^{3}$. \\ Dieter Edbauer ${ }^{1,11}$. Christian Haass 1,3,11 $^{1,1}$
}

Received: 29 May 2019 / Revised: 30 September 2019 / Accepted: 1 October 2019 / Published online: 23 October 2019

(c) The Author(s) 2019

\begin{abstract}
Repeat expansion in C9orf72 causes amyotrophic lateral sclerosis and frontotemporal lobar degeneration. Expanded sense and antisense repeat RNA transcripts in C9orf72 are translated into five dipeptide-repeat proteins (DPRs) in an AUG-independent manner. We previously identified the heterogeneous ribonucleoprotein (hnRNP) A3 as an interactor of the sense repeat RNA that reduces its translation into DPRs. Furthermore, we found that hnRNPA3 is depleted from the nucleus and partially mislocalized to cytoplasmic poly-GA inclusions in C9orf72 patients, suggesting that poly-GA sequesters hnRNPA3 within the cytoplasm. We now demonstrate that hnRNPA3 also binds to the antisense repeat RNA. Both DPR production and deposition from sense and antisense RNA repeats are increased upon hnRNPA3 reduction. All DPRs induced DNA double strand breaks (DSB), which was further enhanced upon reduction of hnRNPA3. Poly-glycine-arginine and poly-proline-arginine increased foci formed by phosphorylated Ataxia Telangiectasia Mutated (pATM), a major sensor of DSBs, whereas polyglycine-alanine (poly-GA) evoked a reduction of pATM foci. In dentate gyri of $C 9$ orf 72 patients, lower nuclear hnRNPA3 levels were associated with increased DNA damage. Moreover, enhanced poly-GA deposition correlated with reduced pATM foci. Since cytoplasmic pATM deposits partially colocalized with poly-GA deposits, these results suggest that poly-GA, the most frequent DPR observed in C9orf72 patients, differentially causes DNA damage and that poly-GA selectively sequesters pATM in the cytoplasm inhibiting its recruitment to sites of DNA damage. Thus, mislocalization of nuclear hnRNPA3 caused by poly-GA leads to increased poly-GA production, which partially depletes pATM, and consequently enhances DSB.
\end{abstract}

Keywords Amyotrophic lateral sclerosis $\cdot$ C9orf72 $\cdot$ DNA damage $\cdot$ Frontotemporal lobar degeneration $\cdot$ Heterogeneous ribonucleoprotein A3 $\cdot$ Neurodegeneration

\section{Introduction}

C9orf72 repeat expansion is the most common cause of autosomal dominant FTLD, FTLD/ALS, and ALS [14, 20, 50]. While unaffected people generally have less than 30 $\left(\mathrm{G}_{4} \mathrm{C}_{2}\right) n$ repeats, mutation carriers have a few hundred or

Electronic supplementary material The online version of this article (https://doi.org/10.1007/s00401-019-02082-0) contains supplementary material, which is available to authorized users.

Christian Haass

christian.haass@mail03.med.uni-muenchen.de

Extended author information available on the last page of the article even thousands of repeats [50]. Sense and antisense repeat RNAs accumulate within intranuclear RNA foci [14]. Furthermore, sense and antisense transcripts are translated in all reading frames into dipeptide-repeat proteins (DPRs) in an AUG-independent manner [2, 43]. Accumulating evidence suggests that neurotoxicity occurs via various cellular pathways, such as RNA mis-splicing and reduced transcription of the C9orf72 gene [27, 29], nucleocytoplasmic transport dysfunction $[19,28,65,66]$, nucleolar stress $[23,38,60]$, and DNA damage [15, 32, 58].

We previously identified the heterogeneous ribonucleoprotein (hnRNP) A3 as an interactor of the sense repeat RNA. We and others also found that hnRNPA3 is mislocalized from the nucleus to the cytoplasm specifically in 
hippocampal, cerebellar, and spinal motor neurons of C9orf72 patients [17, 41]. Moreover, mislocalized hnRNPA3 colocalizes with poly-glycine-alanine (poly-GA) deposits [42]. Reduction of nuclear hnRNPA3 increases $\left(\mathrm{G}_{4} \mathrm{C}_{2}\right)$ repeat RNA foci. Furthermore, repeat RNA foci and DPRs may enhance nucleocytoplasmic transport dysfunction, reducing nuclear hnRNPA3 and thus initiating a vicious cycle [42]. Thus, reduction of nuclear hnRNPA3 may be specifically associated with $C 9$ orf 72 -dependent neurotoxicity, though the cellular mechanisms remain unclear. There is evidence that $C 9$ orf72-linked neurotoxicity is driven by genomic instability [58]. Moreover, impairment of DNA damage repair is implicated in several other neurodegenerative diseases, such as Alzheimer disease, Parkinson's disease, and Huntington disease $[6,8,9,11,21,25,33,34$, $36,64]$. DNA double strand breaks (DSBs) are the most severe type of DNA damage and frequently lead to cell death if not correctly repaired. Homologous recombination (HR) and non-homologous end joining (NHEJ) are the two major cellular mechanisms that repair DSBs in mammalian cells. HR fully restores the original sequence using the sister chromatid as a template, but is, therefore, limited to the late $\mathrm{S}$ to $\mathrm{G} 2 / \mathrm{M}$ phase of the cell cycle [37, 61]. NHEJ is a rather error-prone repair mechanism that rejoins broken DNA ends without a template DNA and can, therefore, occur throughout the cell cycle [47]. Since neurons are arrested in the G0 phase and are non-proliferative, their main repair mechanism is limited to NHEJ. Due to their error-prone repair pathway, neurons are quite vulnerable to DNA damage. This may be particularly important for expanded $C 9$ orf 72 repeats, as they form G-quadruplex structures and promote the formation of RNA:DNA hybrids (R-loops) [18, 23, 63], which are prone to DSBs. Walker et al. reported that expanded hexanucleotide repeats and poly-GA impair Ataxia Telangiectasia Mutated (ATM)-mediated DNA repair [58]. Moreover, reduced expression of hnRNPA3 itself may enhance DSBs [13]. Furthermore, many hnRNPs, which are genetically associated with FTD/ALS, such as hnRNPA1, A2B1, and FUS (hnRNPP2) are reported to be involved in DNA damage and repair [4, 12, 24, 44, 48, 55], and hnRNPA3 is a homolog of hnRNPA1 and A2B1 $[9,59]$. We speculated that cytoplasmic mislocalization of hnRNPA3 may affect ATMmediated DNA damage directly [13] via increased repeat RNA foci and DPR production. We now investigated the association of hnRNPA3 expression, RNA foci formation, DPR production, and DNA damage in cultured cells, including patient-derived human neurons and brains of $C 9$ orf 72 carriers. Our findings suggest that the most frequent DPRs (poly-GA) observed in $C 9$ orf 72 patients differentially cause DNA damage by selectively sequestering phosphorylated ATM (pATM) in the cytoplasm and inhibiting its recruitment to sites of DNA damage.

\section{Materials and methods}

\section{DNA synthesis and plasmid construction for in vitro transcription}

We synthesized the plasmid containing hexanucleotide repeats for in vitro transcription by using a previously reported protocol [41]. In brief, 124 base single-stranded DNA containing $\mathrm{G}_{4} \mathrm{C}_{2}, \mathrm{C}_{4} \mathrm{G}_{2}$, or $\mathrm{A}_{4} \mathrm{C}_{2}$ hexanucleotide repeats with restriction enzyme sites (NheI or HindIII) were synthesized (Suppl. Fig. 1a). $100 \mu \mathrm{M}$ of complementary DNA strands were annealed in the presence of $10 \%$ GC-RICH solution (Roche) and GC-RICH PCR Reaction buffer (Roche) and cloned into pcDNA3.1(+) vector (Invitrogen). Plasmids containing 17 repeats of $\mathrm{G}_{4} \mathrm{C}_{2}, \mathrm{C}_{4} \mathrm{G}_{2}$, and $\mathrm{A}_{4} \mathrm{C}_{2}$ were obtained. The DNA sequence of all constructs was verified.

\section{In vitro transcription of RNA probes}

pcDNA3.1- $\left(\mathrm{G}_{4} \mathrm{C}_{2}\right) 17$, pcDNA3.1- $\left(\mathrm{C}_{4} \mathrm{G}_{2}\right) 17$, and pcDNA3.1$\left(\mathrm{A}_{4} \mathrm{C}_{2}\right) 17$ constructs were linearized with HindIII and used as templates for RNA synthesis (Suppl. Fig. 1a). In vitro RNA transcription was performed with T7 Ribomax Express Large Scale RNA Production System (Promega) supplemented with $40 \mathrm{U}$ of RNase inhibitor (RiboLock, Thermo Scientific) as described by the manufacturer. To achieve equal levels of biotinylation between these probes, different concentrations of biotin-14-CTP $\left(1 \mathrm{mM}\right.$ for $\mathrm{G}_{4} \mathrm{C}_{2}$ probe, $0.08 \mathrm{mM}$ for $\mathrm{C}_{4} \mathrm{G}_{2}$ probe, and $1.2 \mathrm{mM}$ for $\mathrm{A}_{4} \mathrm{C}_{2}$ probe) were added in each reaction. Following DNase treatment, biotinylated RNA products were purified with phenol/chloroform. For competition experiments non-biotinylated $\mathrm{C}_{4} \mathrm{G}_{2}$ repeat RNA was in vitro RNA transcribed using the MEGA script kit (Ambion) as described by the manufacturer. The expected lengths of repeat RNA probes and competitor were confirmed by formaldehyde gel electrophoresis (Suppl. Fig. 1b). Biotinylation efficacy of RNA probes was evaluated using the BrightStar BioDetect kit (Ambion) (Suppl. Fig. 1c).

\section{Purification of hexanucleotide repeat-binding proteins}

Purification of hexanucleotide repeat-binding proteins was performed following our previously described protocol [41]. In brief, a total of $0.6 \mathrm{mg}$ of HeLa cell nuclear extract was diluted in $4 \mathrm{ml}$ of protein-binding buffer $(10 \%$ glycerol, $10 \mathrm{mM}$ HEPES, $50 \mathrm{mM} \mathrm{KCl}, 1 \mathrm{U} / \mathrm{ml}$ RNase inhibitor, 0.15 $\mathrm{lg} / \mathrm{ml}$ yeast tRNA (10109495001, Roche), $1 \mathrm{mM}$ EDTA, $1 \mathrm{mM}$ DTT and $0.5 \%$ Triton X100 in DEPC water). The diluted extract was then precleared with heparin-agarose 
(H6508, Sigma-Aldrich) and streptavidin-agarose (15942050, Invitrogen). The precleared nuclear extracts were incubated with streptavidin $\mu$ MACS-microbeads (MACS molecular) and 150 pmol of biotinylated repeat RNA in the presence of $50 \mathrm{mM} \mathrm{KCl}$ for $1 \mathrm{~h}$. For competition experiments, nuclear extracts were incubated for $1 \mathrm{~h}$ with $7.5 \mathrm{nmol}$ (50-fold excess) of non-biotinylated $\left(\mathrm{C}_{4} \mathrm{G}_{2}\right) 17$ competitor RNA before addition of the biotinylated probe. The reaction mixture was loaded on a $\mu$ MACS column and subsequently washed three times with protein-binding buffer. Hexanucleotide repeat binding proteins were sequentially eluted with increasing concentrations of $\mathrm{NaCl}$. Each eluate was TCA precipitated and subjected to SDS-PAGE.

\section{Cell culture}

HeLa cells were cultured in DMEM containing 10\% FCS and Penicillin/Streptomycin at $37{ }^{\circ} \mathrm{C}$ with $5 \% \mathrm{CO}_{2}$.

\section{Patient-derived fibroblasts}

We included cell lines from 3 C9orf72 ALS patients and 3 control cases from our previous report [42]. All procedures were in accordance with the Helsinki convention and approved by the Ethical Committee of the University of Dresden (EK45022009; EK393122012). Patients were genotyped using EDTA blood in the clinical setting after given written consent according to German legislation independent of any scientific study by a diagnostic human genetic laboratory (CEGAT, Tübingen, Germany or Department of Human Genetics, University of Ulm, Germany) using diagnostic standards.

For further details of patients' background, see Suppl. Table 1.

\section{siRNA-mediated knockdown in fibroblasts and iPSC-derived neurons}

The following siRNAs were obtained from Dharmacon: ONTARGETplus human non-targeting siRNA D-001810-01, hnRNPA3 J-019347-08 ACAAUGAAGGAGGAAAUUU, hnRNPA3 J-019347-06 GGAGGGAACUUUGGAGGU G. $10 \mathrm{nMol}$ of each siRNA was reverse transfected using RNAiMax (Thermo Fisher Scientific) and OPTI-MEM. Media were exchanged after overnight incubation. Cells on coverslips were fixed on the next day ( $48 \mathrm{~h}$ after a transfection of siRNA containing solution).

\section{Plasmid transfection}

For plasmid transfection in HeLa cells, $0.5 \mu \mathrm{g} / \mathrm{well}$ (in the case of 24-well plate) of DNA was transfected with lipofectamine LTX with plus reagent (Thermo Fisher Scientific) in OPTI-MEM. Plasmid containing media were exchanged after $6 \mathrm{~h}$-incubation. Cells were harvested $48 \mathrm{~h}$ after plasmid transfection.

\section{Fluorescence in situ hybridization for antisense RNA foci}

Fluorescence in situ hybridization (FISH) was performed as previously described $[39,42,51]$ with slight modifications. $2 \%$ paraformaldehyde fixed and perforated cells on glass coverslips were rinsed twice with $2 \times$ saline-sodium citrate buffer (SSC) and then incubated in prehybridization solution (40\% formamide (Life Technologies, 15515-026)/2 $\times$ SSC, $2.5 \%$ bovine serum albumin (BSA)) at $57^{\circ} \mathrm{C}$ for $30 \mathrm{~min}$. Cells were then incubated with hybridization solution $(40 \%$ formamide, $2 \times \mathrm{SSC}, 0.8 \mathrm{mg} / \mathrm{ml}$ tRNA (Roche), $0.8 \mathrm{mg} /$ $\mathrm{ml}$ single strand salmon sperm DNA (Sigma-Aldrich, D7656), 0.16\% BSA, 8\% Dextran sulfate (Sigma-Aldrich), $1.6 \mathrm{mM}$ Ribonucleoside vanadyl complex (New England Biolabs, S1402S), $5 \mathrm{mM}$ EDTA, $10 \mathrm{ng} / \mathrm{ml}$ 5' Cy3-labbeled $2^{\prime}$-O-methyl-(CCGGGG) $\times 4$ probe (IDT)) at $57^{\circ} \mathrm{C}$. The following day, cells were sequentially washed in $40 \%$ formamide $/ 0.5 \times \mathrm{SSC}$ for 3 times $30 \mathrm{~min}$ each at $57{ }^{\circ} \mathrm{C}$ and then with $0.5 \times \mathrm{SSC} 3$ times $10 \mathrm{~min}$ each at room temperature. After a brief rinse with PBS, nuclei were counterstained with $0.5 \mu \mathrm{g} / \mathrm{ml}$ of DAPI for $20 \mathrm{~min}$ and then washed with PBS for 3 times 3 min each. Glass coverslips were mounted using Prolong Gold antifade (Life Technologies) and analyzed with LSM710 confocal microscopy with ZEN2011 software (Zeiss). For FISH of fibroblasts, after incubation with hybridization solution and washing, blocking with 5\% FCS (30 min) and nucleolin (NCL) staining ( $4{ }^{\circ} \mathrm{C}$ overnight) was performed. Nuclei were counterstained with DAPI and glass coverslips were mounted on the following day.

\section{Differentiation of human neural precursor cells (NPCs) to spinal motor neurons (MNs)}

The generation of all iPSCs was recently published $[22,26$, 52]. The generation of human NPCs and MNs was accomplished following the protocol from Naumann et al. [44]. In brief, colonies of iPSCs were collected and stem cell medium, containing $10 \mu \mathrm{M} \mathrm{SB}-431542,1 \mu \mathrm{M}$ Dorsomorphin, $3 \mu \mathrm{M}$ CHIR 99021 and $0.5 \mu \mathrm{M}$ pumorphamine (PMA), was added. After 2 days hESC medium was replaced with basal media (DMEM-F12/Neurobasal 50:50 with 1:200 N2 Supplement, 1:100 B27 lacking Vitamin A and 1\% penicillin/streptomycin/glutamine). On day $4150 \mu \mathrm{M}$ ascorbic acid was added, while Dorsomorphin and SB-431542 were withdrawn. 2 Days later the EBs were mechanically separated and replated on Matrigel coated dishes. For this purpose, Matrigel was diluted (1:100) in DMEM-F12 and kept on the dishes over night at room temperature. Possessing a 
ventralized and caudalized character the arising so called small molecule NPCs (smNPC) formed homogenous colonies during the course of further cultivation. It was necessary to split them at a ratio of 1:10-1:20 once a week using Accutase for $10 \mathrm{~min}$ at $37{ }^{\circ} \mathrm{C}$.

To identify $\mathrm{Hb} 9$-positive neurons, we transduced the $\mathrm{Hb} 9:$ :GFP promoter into the neural progenitor cells using a lentivirus system [30, 45], and the resulting neural progenitors were replated on Poly-L-Ornithine / laminin coated dish and cultured in basal media supplemented with $1 \mu \mathrm{M}$ PMA. After 2 days $1 \mu \mathrm{M}$ retinoic acid (RA) was added. On day 9 another split was performed to seed them on a desired cell culture system. Furthermore, the medium was modified to induce neural maturation. For this purpose, the developing neurons were treated with N2B27 containing $10 \mathrm{ng} / \mu \mathrm{l}$ BDNF, $500 \mu \mathrm{M}$ dbcAMP and $10 \mathrm{ng} / \mu \mathrm{l}$ GDNF. Finally, motor neuron differentiation was confirmed by immunocytochemistry.

\section{Plasmids}

The $\left(\mathrm{G}_{4} \mathrm{C}_{2}\right)_{80}$ and $\left(\mathrm{C}_{4} \mathrm{G}_{2}\right)_{30}$ expression vectors are based on a previously published cDNA construct [42]. The modified vector expresses $\left(\mathrm{C}_{4} \mathrm{G}_{2}\right)_{30}$ under the control of the CMV promoter including $620 \mathrm{bp}$ of the $5^{\prime}$ flanking region of the human $C 9$ orf $72 \mathrm{C}_{4} \mathrm{G}_{2}$ repeat which was PCR subcloned from patient fibroblast derived genomic DNA. This patient has a GGGCCCGCCCCC insertion just before the beginning of the CCCCGG repeat, where frequent sequence variations have been observed [40, 46, 57]. The 5' flanking region contains multiple stop codons in each reading frame.

Synthetic DPR constructs containing an ATG start codon for transient expressions in HeLa cells were constructed as previously described [7] with slight modifications. Codon optimized DNA sequences encoding 12 repeats of each DPR, were designed. Restriction sites for XhoI-FokI and BbsI-XbaI were placed at the beginning and end of the DNA oligonucleotide. The synthesized DNA oligonucleotide was subcloned into the pEGFP-C1 vector (Clontech) using XhoI and $\mathrm{XbaI}$ sites. The codon optimized 11 repeat coding fragments were isolated through double digestion with FokI and BbsI, and then ligated into BbsI site of the parental 12 repeats vector to double the repeat-length. This was repeated until $175-177$ repeats were achieved $(12+11=23$ repeats, $23+22=45$ repeats, $45+44=89$ repeats, $89+86=175$ repeats (poly-GA), $89+88=177$ repeats (poly-glycine-arginine: poly-GR), $89+87=176$ repeats (poly-proline-arginine: poly-PR). The repeat number differences at the last step are due to clonal instability). The following oligonucleotides were used.
XhoI-FokI-GA12-BbsI-XbaI: 5'-CTCGAGGGATGT TGAATTCTGGTGCTGGCGCGGGAGCAGGCGCTG GTG CTGGTGCAGGAG CGG GTG CGGGAG CTG GTGCCGGCGCAGGTGCTGTCTTCGGATCCTAGT CTAGA-3'.

XhoI-FokI-GR12-BbsI-XbaI: 5'-CTCGAGGGATGT TGAATTCTGGTCGTGGACGTGGACGAGGTCGAGGTC GAGGTCGTGGACGTGGTCGAGGTCGAGGTCGTG GACGTGGTCGTGTCTTCGGATCCTAGTCTAGA-3'.

XhoI-FokI-PR12-BbsI-XbaI: 5'-CTCGAGGGATGTTGA ATTCTCCGCGACCTCGACCGCGGCCACGCCCACGCC CTCGGCCCAGACCACGTCCTAGGCCCAGACCCAGAC CGCGAGTCTTCGGATCCTAGTCTAGA-3'.

Synthetic DPR constructs containing an ATG start codon for lentiviral expression (synapsin promoter) and transient transfection (EF1 promoter) were described before [9].

\section{Crispr/Cas9 genome editing}

Knockout of hnRNPA3 was performed in HeLa cells using the Crispr/Cas9 [49]. Guide RNA sequences targeting hnRNPA3 genetic loci were designed using the gRNA tool from the Zhang laboratory [https://crispr.mit.edu (Suppl. Fig. 2a)]. Duplexed sgRNA oligos were digested and ligated into pSpCas9(BB)-2A-Puro (PX459) to generate hnRNPA3 Puro plasmid. CRISPR knock-out cells were generated by transfection with hnRNPA3 Puro plasmid followed by selection with $1 \mu \mathrm{g} / \mathrm{ml}$ puromycin. Individual clones were generated by plating cells at low density and isolating individual colonies. hnRNPA3 knockout was confirmed by DNA sequencing (Suppl. Fig. 2b) and western blotting (Fig. 2a). For sequencing of hnRNPA3, genomic loci were amplified by PCR using the following primers:

Forward: 5'-GTATGTCAGCCGCGTTTT-3', Reverse: 5'- CGGCGGATCAATGTCAAT-3'.

\section{Western blotting}

To detect the protein expression (except for pATM), samples were separated on $12 \%$ Tris-glycine gel and transferred on PVDF membranes. After blocking for $1 \mathrm{~h}$ with $0.2 \%$ I-Block (Applied Biosystems) in TBST (TBS with $0.5 \%$ Tween 20), membranes were incubated with indicated antibody overnight. The antibody signal was detected with HRP-conjugated secondary antibodies (Promega) using the ECL reagents (GE healthcare) and exposed to X-ray films (SuperRX, Fujifilm).

For detection of pATM, samples were separated on NuPAGE 3-8\% Tris-Acetate protein gel (Invitrogen) and transferred on PVDF membrane with $25 \mathrm{~V}$ for $15 \mathrm{~h}$. After 
blocking for $1 \mathrm{~h}$ with 5\% PhosphoBLOCKER (Cell Biolabs, AKR-104) in TBST, membranes were incubated with indicated antibody for $2 \mathrm{~h}$ at room temperature. All subsequent steps were performed as described above.

\section{Co-immunoprecipitation (co-IP)}

HeLa cells were lysed in co-IP buffer $(150 \mathrm{mM} \mathrm{NaCl}$, $50 \mathrm{mM}$ Tris- $\mathrm{HCl} \mathrm{pH} 7.4,0.5 \%$ NP-40, 0.5\% Na deoxycholate, 5 mM EDTA) supplemented with EDTA-free Protease Inhibitor Cocktail (Roche, 04693132 001) and PhosSTOP (Roche, 04906845 001), then incubated for $30 \mathrm{~min}$ on ice. Lysates were centrifuged for $5 \mathrm{~min}$ at $5000 \mathrm{rpm}$, and the supernatant was collected. For co-IP, the Dynabeads Protein G immunoprecipitation kit (Invitrogen, 10007D) was used. The bead-antibody-antigen complex was isolated using a magnetic tool (Invitrogen, 12321D) and resuspended in elution buffer and NuPAGE LDS sample buffer (Invitrogen, NP0007) supplemented with DTT. The complex was heated for $10 \mathrm{~min}$ at $70{ }^{\circ} \mathrm{C}$ and captured proteins were separated from bead-antibody complexes using a magnetic tool. Isolated antigens were analyzed by western blotting.

\section{Cell fractionation}

Cell fractionation was performed as previously described [5]. Briefly, cells were washed twice in ice-cold PBS. Cells were harvested in $400 \mu \mathrm{l}$ buffer 1 (50 mM Tris ( $\mathrm{pH} 7.9$ ), $10 \mathrm{mM} \mathrm{KCl}, 1 \mathrm{mM}$ EDTA, $0.05 \%$ NP-40, 10\% glycerol and protease/phosphatase inhibitors) and centrifuged at 6,000 r.p.m. for $3 \mathrm{~min}$ at $4{ }^{\circ} \mathrm{C}$. The supernatants were used for the analysis of cytoplasmic proteins. The nuclear pellet was lysed with $150 \mu$ l buffer 2 (20 mM HEPES (pH 7.9), $400 \mathrm{mM} \mathrm{NaCl}, 10 \mathrm{mM} \mathrm{KCl}, 1 \%$ NP-40, 20\% glycerol, $1 \mathrm{mM}$ EDTA and protease/phosphatase inhibitors) for $20 \mathrm{~min}$ at $4{ }^{\circ} \mathrm{C}$, then centrifuged at 14,000 r.p.m. for $10 \mathrm{~min}$. The supernatants were used for the analysis of nuclear proteins.

\section{Immunofluorescent staining for HeLa cells and neurons}

Cells on glass coverslips were washed with PBS and fixed with $4 \%$ PFA for $15 \mathrm{~min}$ on ice and permeabilized with $0.2 \%$ Triton-X100 in PBS for $5 \mathrm{~min}$ at room temperature. After that cover slips were washed with PBS 3 times and blocked with 5\%FCS in PBS. Primary antibody incubation was performed overnight at $4{ }^{\circ} \mathrm{C}$, and incubation of secondary antibody conjugated with Alexa Fluor 555 or Alexa Fluor 488 (anti-rabbit, anti-mouse, and anti-rat) was performed for $1 \mathrm{~h}$ at room temperature. After a brief rinse with PBS, nuclei were counterstained with $0.5 \mu \mathrm{g} / \mathrm{ml}$ of DAPI for $20 \mathrm{~min}$ and then washed with PBS for 3 times 5 min. Finally, coverslips were mounted using Prolong Gold antifade (Life Technologies).

\section{Quantitative immunofluorescence in HeLa cells and neurons}

Three to ten fluorescent images of HeLa cells and cultured neurons were obtained from each glass coverslip using LSM710 (Zeiss) microscope with a $63 \times$ oil immersion objective. Raw data tif files of each channel were exported from czi files using Zen2011 software. Quantification was performed using ImageJ software. The numbers of $\gamma \mathrm{H} 2 \mathrm{AX}$ foci positive HeLa cells and iPSC-derived neurons were determined with cell counter plugin of Image $\mathrm{J}$.

\section{Human brain samples}

All cases were provided by the Neurobiobank Munich, Ludwig-Maximilians-University (LMU) Munich, Germany and the ALS Tissue Bank Kantonspital St. Gallen, Switzerland and collected and distributed according to the guidelines of the local ethics committees. Autopsies were performed on basis of informed consent. For further details, see Table 1.

\section{Immunofluorescent staining for human brain sections}

Immunohistochemical staining was performed on $5 \mu \mathrm{m}$-thick paraffin sections. Following antigen retrieval by microwaving for $30 \mathrm{~min}$ in citrate buffer $(10 \mathrm{mM}$ citric acid, $0.05 \%$ Tween20, pH 6.2) for co-staining of hnRNPA3 and poly-GA, or citrate-EDTA buffer (10 mM citric acid, $2 \mathrm{mM}$ EDTA, $0.05 \%$ Tween $20, \mathrm{pH} 6.2$ ) for all other stainings and settling the sections at room temperature for $20 \mathrm{~min}$, sections were rinsed with PBS-Tween 20 for 2 min, 2 times. After blocking with 2\% FCS in PBS for 30 min, sections were incubated in primary antibody overnight at $4{ }^{\circ} \mathrm{C}$. Sections were then rinsed with PBS for $5 \mathrm{~min}, 3$ times, and then incubated in secondary antibody solution for $1 \mathrm{~h}$ at room temperature. After rinsing with PBS 2 times, 2.5 min each, nuclei were counterstained with $0.5 \mu \mathrm{g} / \mathrm{ml}$ of DAPI for $20 \mathrm{~min}$ and sections were then washed with PBS for 2 times 2.5 min each. To reduce autofluorescence, slides were incubated with $0.3 \%$ Sudan Black in $70 \%$ ethanol for 1 min. After a rinse with tap water, sections were mounted with using Prolong Gold antifade (Life Technologies). 
Table 1 Demographics of postmortem cases used in the neuropathological study

\begin{tabular}{|c|c|c|c|c|c|c|c|c|}
\hline Case & Case no & Source & Gender & $\begin{array}{l}\text { Age at disease } \\
\text { onset (years) }\end{array}$ & $\begin{array}{l}\text { Age at } \\
\text { death } \\
\text { (years) }\end{array}$ & Clinical diagnosis & $\begin{array}{l}\text { Fixation } \\
\text { time (days) }\end{array}$ & $\begin{array}{l}\text { Post mor- } \\
\text { tem time } \\
\text { (h) }\end{array}$ \\
\hline C9 & 1 & Munich & male & 45 & 49 & ALS without dementia & 98 & 26 \\
\hline C9 & 2 & Munich & male & 45 & 47 & bvFTD & $<59$ & 21 \\
\hline C9 & 3 & Munich & female & 68 & 81 & FTD + Depression & 287 & 102 \\
\hline C9 & 4 & St. Gallen & male & 71 & 72 & ALS Without dementia & 7 & 8.5 \\
\hline C9 & 5 & Munich & male & 67 & 69 & Dementia with Lewy bodies & 69 & $36-60$ \\
\hline C9 & 6 & Munich & male & 55 & 61 & $\mathrm{CBD}$ & 210 & 33 \\
\hline C9 & 7 & Munich & female & 50 & 58 & Dementia & n.i & 19 \\
\hline C9 & 8 & Munich & male & 68 & 76 & Pick's disease (Dementia) & 35 & 130 \\
\hline C9 & 9 & Munich & male & $<64$ & 68 & Dementia with Lewy Bodies + Parkinson & 42 & 192 \\
\hline C9 & 10 & Munich & male & 60 & 65 & Atypical Parkinsonism + semantic dementia & 87 & 30 \\
\hline C9 & 11 & Munich & female & 58 & 59 & Bulbar MND + beginning bvFTD & 87 & 46 \\
\hline C9 & 12 & Munich & male & n.i. & 74 & FTD & 40 & 37 \\
\hline C9 & 13 & Munich & male & 54 & 57 & bvFTD (Pick) & $<135$ & 22 \\
\hline C9 & 14 & Munich & female & 60 & 63 & ALS Without dementia & 56 & 37 \\
\hline C9 & 15 & St. Gallen & female & 62 & 66 & ALS Without dementia & 7 & 2 \\
\hline C9 & 16 & Munich & female & 46 & 46 & ALS Without dementia & 19 & 20 \\
\hline $\mathrm{Ct}$ & 1 & Munich & male & n.a. & 61 & n.a. & 7 & $10-34$ \\
\hline $\mathrm{Ct}$ & 2 & Munich & male & n.a. & 46 & n.a. & 10 & $10-34$ \\
\hline $\mathrm{Ct}$ & 3 & Munich & male & n.a. & 62 & n.a. & 430 & 46 \\
\hline $\mathrm{Ct}$ & 4 & Munich & male & n.a. & 82 & n.a. & 63 & 63 \\
\hline $\mathrm{Ct}$ & 5 & Munich & female & n.a. & 73 & n.a. & 111 & 16 \\
\hline $\mathrm{Ct}$ & 6 & Munich & male & n.a. & 74 & n.a. & 274 & 33 \\
\hline $\mathrm{Ct}$ & 7 & Munich & male & n.a. & 67 & n.a. & 20 & $25-31$ \\
\hline $\mathrm{Ct}$ & 8 & Munich & male & n.a. & 58 & n.a. & 154 & 22 \\
\hline $\mathrm{Ct}$ & 9 & Munich & male & n.a. & 63 & n.a. & 4 & 18 \\
\hline
\end{tabular}

$A L S$ amyotrophic lateral sclerosis, $b v F T D$ frontotemporal dementia behavioural variant, $C B D$ corticobasal degeneration, $F T D$ frontotemporal dementia, $M N D$ motoneuron disease, $n . a$. not applicable, n.i. no information

\section{Quantitative immunofluorescence in human brain sections}

To quantify nuclear hnRNPA3 signal intensity in granular cells of human dentate gyri, we followed the protocol that we previously reported [42]. Fluorescent images of three different areas of hippocampal dentate gyrus granular cell layer at the level of lateral geniculate body were obtained from each case as indicated in Suppl. Fig. 3 using a LSM710 (Zeiss) microscope with a $63 \times$ oil immersion objective. One image was shot for each area. Raw data tif files of each channel were exported from czi files using Zen2011 software. Quantification was performed using ImageJ software. Binary images from DAPI staining were used for the nuclear regions. Vascular structures were manually excluded from the analysis. Granular cell numbers of each image were counted. Nuclear hnRNPA3 was defined as hnRNPA3 signal overlapping with DAPI staining. The hnRNPA3 signal from structures outside of cell bodies was regarded as background. After subtraction of background, nuclear hnRNPA3 intensities of 242-636 granular layer cells/case were quantified in 16 C9orf 72 cases. Median nuclear hnRNPA3 intensities (arbitrary unit) of these cells per micrograph were defined as the nuclear hnRNPA3 level of each image. An average of the nuclear hnRNPA3 levels of 3 micrographs from a $C 9$ orf 72 case was regarded as the nuclear hnRNPA3 level of the case. The numbers of $\gamma \mathrm{H} 2 \mathrm{AX}$ foci positive cells, poly-GA aggregates positive cells, and pATM foci positive cells were determined by cell counter, the plugin of ImageJ software.

\section{Filter trap analysis in HeLa cells}

Cells cultured in 6-well plates were lysed in $600 \mu \mathrm{l}$ lysis buffer (25 mM HEPES pH 7.6, $150 \mathrm{mM} \mathrm{NaCl}, 3 \%$ SDS, $0.5 \%$ sodium deoxycholate, $1 \%$ Triton $\mathrm{X}-100)$ supplemented with protease inhibitor cocktail (Sigma-Aldrich) for $10 \mathrm{~min}$ and passed through $27 \mathrm{G}$ needle for 10 times. The lysates were further diluted to $2 \mu \mathrm{g}$ or $0.5 \mu \mathrm{g}$ protein per $200 \mu \mathrm{l}$ with lysis buffer. $100 \mu \mathrm{l}$ of each sample were filtered through 
a nitrocellulose membrane ( $0.45 \mu \mathrm{m}$ pore). The membrane was subsequently washed once with TBST, and then blocked in I-Block/TBS/0.5\% TritonX-100. Levels of each DPR were analyzed with antibodies against each three different tag (FLAG, myc, HA). Quantified signals from 2 or 3 independent filter trap analyses probed with 3 different tag antibodies (total 6 or 8 membranes) are shown as fold expression.

\section{Antibodies}

The following antibodies were used for Western blotting (WB), immunoprecipitation (IP), and immunofluorescence (IF): anti-hnRNP A1 antibody, clone 4B10 (Sigma-Aldrich, 05-1521) WB 1/8,000, anti-hnRNP A2/B1 antibody, clone DP3B3 (Sigma-Aldrich, R4653) WB 1/10,000, anti-hnRNP A3 antibody, ab1 (Sigma-Aldrich, AV41195, lot No. QC10071) WB 1/2,000 and 1/150 (human brain sections), anti-DYKDDDDK(FLAG) Tag antibody (Cell Signaling \#2368S) WB 1/1,000, anti-myc clone 9E10 (Santa Cruz, sc-40) WB 1/1,000, anti-HA Tag antibody, clone 3F10 (Roche, 12158167001) WB 1/1,000, anti-GFP antibody, clone N86/8 (Neuromab) WB 1/3,000, anti-GFP antibody (abcam, ab6556) IF 1/2,000, anti-GFP antibody (Novus Biologicals, NB100-1770) IF 1/200, anti- $\beta$-actin antibody (Sigma-Aldrich, A5316) WB 1/2,000, anti-tubulin $\beta$ III antibody, clone 2G10 (Millipore, 05-559) WB 1/5,000, IF 1/200, anti-NCL antibody (Abcam, ab136649) IF 1/1,000, antiphospho-Histone H2A.X (Ser139) antibody, clone JBW301 (Merck Millipore, 05-636) IF 1/250 (for HeLa cells and human brain sections), anti-ATM (phospho S1981) antibody (abcam, ab81292) IP 1/30, WB 1/2,500, anti-ATM (phospho S1981) antibody (abcam, ab36810) IF 1/250, anti-FUS antibody (Bethyl, A300-294A) IF 1/1,500, anti-HuR antibody (SantaCruz, sc-5261) IF 1/100, anti- $\alpha$-tubulin (SigmaAldrich, T5168) WB 1/4,000, anti-Lamin A/C antibody (Cell Signaling, \#2032) WB 1/1,000 and anti-GA antibody (Mackenzie et al. [35]) IF 1/500.

\section{Quantitative reverse transcription PCR (qPCR)}

We performed qPCR following the protocol from our previous report [42]. Total RNA was prepared using the RNeasy and Qiashredder kit (Qiagen). RNA preparations were treated with Turbo DNA-free kit (Thermo Fisher Scientific) to minimize residual DNA contamination. Two micrograms of RNA were used for reverse transcription with M-MLV Reverse Transcriptase (Promega) using oligo-(dT) 12-18 primer (Invitrogen). qPCR was performed using the 7500 Fast Real-Time PCR System (Applied Biosystems) with TaqMan technology. Primers and probes were designed (IDT) for the detection of a region flanking the TAG $3^{\prime}$ of the $\mathrm{G}_{4} \mathrm{C}_{2}$ repeat of repeat constructs (repeat TAG primer). Sense repeat, primer 1: TCT CAA ACT GGG ATG CGT
AC, primer 2: GTA GTC AAG CGT AGT CTG GG, probe: 5'-/56-FAM/TG CAG ATA T/Zen/C CAG CAC AGT GGC G/3IABkFQ/-3'. Antisense repeat, primer 1: CAA ACC CGG GTA CCC ATA C, primer 2: CGG GCC CTC TAG ACT ACT T, probe: 5'-/56-FAM/ACG TCC CAG/Zen/ACT ACG CTT GAC TAC A/3IABkFQ/-3'. A primer/probe set for Human GAPDH, 4326317E (Applied Biosystems) was used as endogenous control. Each sample was paired with no reverse transcription controls showing $<1 / 2^{10}(\Delta \mathrm{CT}>10)$ signal when compared to reverse transcribed samples, thus excluding contamination of plasmid DNA-derived signal. Signals from repeat construct derived cDNAs were normalized to GAPDH cDNA according to the $\Delta \Delta \mathrm{CT}$ method.

\section{Statistics}

Statistical analysis was performed using IBM SPSS Statistics 23 software. All statistical results are shown in Suppl. Table 2 .

\section{Results}

\section{hnRNPA3 binds to the C9orf72 antisense repeat RNA}

We previously reported that hnRNPA3 binds to the sense repeat RNA and that reduction of hnRNPA3 increases sense repeat RNA foci [41, 42]. We now investigated if hnRNPA3 also binds to the antisense repeat RNA and if reduction of hnRNPA3 increases the number of antisense repeat RNA foci. To verify binding of hnRNPA3 to the antisense repeat RNA, we performed RNA pull down assays using in vitrotranscribed biotinylated RNAs containing either 17 GGG GCC $\left(\mathrm{G}_{4} \mathrm{C}_{2}\right.$; sense), 17 CCCCGG $\left(\mathrm{C}_{4} \mathrm{G}_{2} ;\right.$ antisense $)$, or 17 AAAACC $\left(\mathrm{A}_{4} \mathrm{C}_{2}\right.$; control) repeats (Suppl. Fig. 1a). Length and amount of the in vitro-transcribed RNA was confirmed by RNA electrophoresis (Suppl. Fig. 1b) and dot blot assays (Suppl. Fig. 1c). Biotinylated in vitro-transcribed RNA probes were incubated with nuclear extracts from HeLa cells in the absence or presence of a 50-fold excess of nonbiotinylated competitor RNA containing the $\mathrm{C}_{4} \mathrm{G}_{2}$ repeat. Bound proteins were eluted using increasing salt concentrations and hnRNPA3 was detected in the eluate by western blotting using an anti-hnRNPA3 polyclonal antibody (Fig. 1a). This elution revealed specific binding of hnRNPA3 not only to the sense but also to the antisense repeat RNA, which was blocked by excess amounts of the non-biotinylated competitor RNA (Fig. 1a). Similarly, the homologous hnRNPA1 [9] also bound specifically to the antisense repeat RNA, and again binding could be significantly reduced by excess amounts of the non-biotinylated competitor RNA (Fig. 1b). Thus, hnRNPA3 interacts with both the sense and the antisense repeat RNA. 


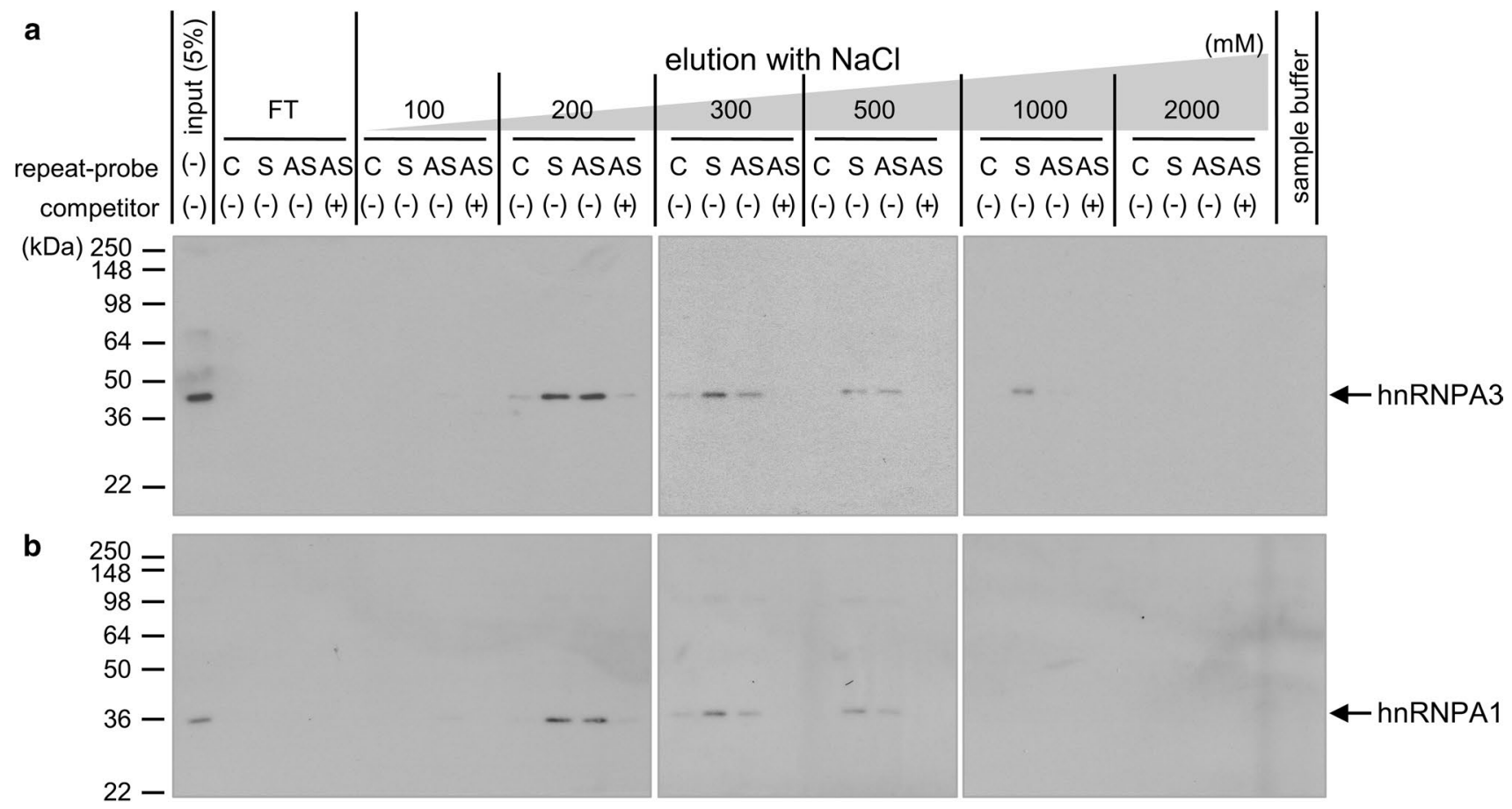

Fig. 1 hnRNPA3 and hnRNPA1 bind to sense and antisense repeat RNAs. Nuclear extracts of HeLa cells were incubated with the indicated biotinylated RNA probes with (+) or without (-) 50-fold excess of non-biotinylated RNA competitor and pulled down by magnet beads. a Western blotting with an anti-hnRNPA3 antibody reveals that hnRNPA3 selectively binds to sense repeats (repeat probe: $S$ ) and antisense repeats (repeat probe: AS), which is inhibited by an

\section{Reduction of hnRNPA3 leads to an increase of antisense RNA foci}

To investigate if reduction of hnRNPA3 leads to increased antisense RNA foci as observed before for sense RNA foci [42], we performed fluorescent in situ hybridization (FISH) using three independent fibroblast lines derived from patients with $C 9$ orf72 repeat expansions [42]. Upon siRNA-mediated hnRNPA3 knockdown (Fig. 2a), the number of foci per cell as well as foci positive cell increased compared to control siRNA or mock-treated cells (Fig. 2b-d). Furthermore, in iPSC-derived human neurons generated from fibroblasts derived from $\mathrm{C} 9$-case 1 and 2, siRNA-mediated knockdown of hnRNPA3 (Fig. 2e) also led to a significant increase of nuclear antisense RNA foci as well RNA foci positive cell (Fig. 2f-h). Thus, reduced nuclear hnRNPA3 leads to increased formation of sense and antisense repeat RNA foci.

\section{hnRNPA3 reduction increases DPR generation from the antisense repeat RNA}

Since knockdown of hnRNPA3 increased not only sense RNA foci [42] but also antisense RNA foci (Fig. 2), we thought that the antisense-derived DPRs poly-PA/PR/GP excess of the non-biotinylated competitor RNA. b Western blotting with an anti-hnRNPA1 antibody reveals that hnRNPA1 binds to sense repeats (repeat probe: $S$ ) and antisense repeats (repeat probe: AS), which is inhibited by an excess of the non-biotinylated competitor RNA. C: $\left(\mathrm{A}_{4} \mathrm{C}_{2}\right)_{17}$-control repeat, $\mathrm{S}$ : $\left(\mathrm{G}_{4} \mathrm{C}_{2}\right)_{17}$-sense repeat, $\mathrm{AS}$ : $\left(\mathrm{C}_{4} \mathrm{G}_{2}\right)_{17}$-antisense repeat

may also increase concomitantly. To prove this, we first generated hnRNPA3 knockout (A3KO) HeLa cells using Crispr/Cas9 gene editing (Suppl. Fig. 2a, b). We verified the introduction of a frame shift followed by a premature stop codon in selected cell clones (Suppl. Fig. 2b) and then confirmed absence of hnRNPA3 expression by western blotting (Fig. 3a). Clone Y-14 was selected and transfected with sense and antisense repeat constructs that express fluorescent tags in all three reading frames of both repeat encoding DNA strands (Fig. 3b). First, we confirmed by qPCR that repeat RNAs from both strands were increased in the absence of hnRNPA3 (Fig. 3c). Re-expression of hnRNPA3 reduced the increase of repeat RNAs observed in the hnRNPA3 knockout (Fig. 3c). We then used filter trap analyses [31] to quantify DPR production. This revealed that all DPRs made from sense and antisense repeat RNA were significantly increased in the absence of hnRNPA3 (Fig. 3d). Thus, reduction of hnRNPA3 increases sense and antisense repeat RNA foci as well as all DPRs translated from sense and antisense repeat RNA. In contrast, overexpression of hnRNPA3 decreased repeat RNAs (Suppl. Fig. 4a) and DPRs (Suppl. Fig. 4b). These findings indicate that hnRNPA3 is strongly associated with the degradation of repeat RNA and subsequent expression of DPRs. 


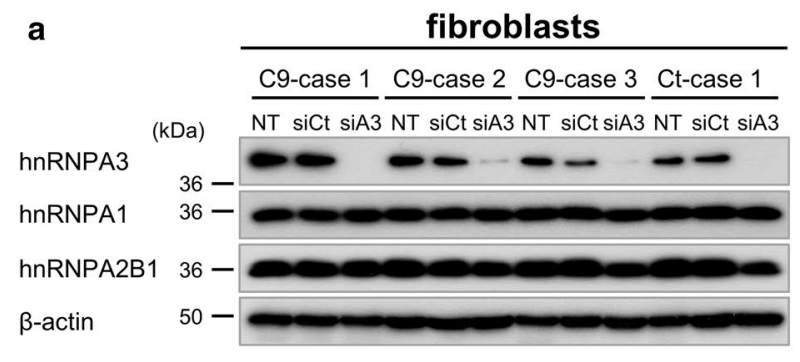

C
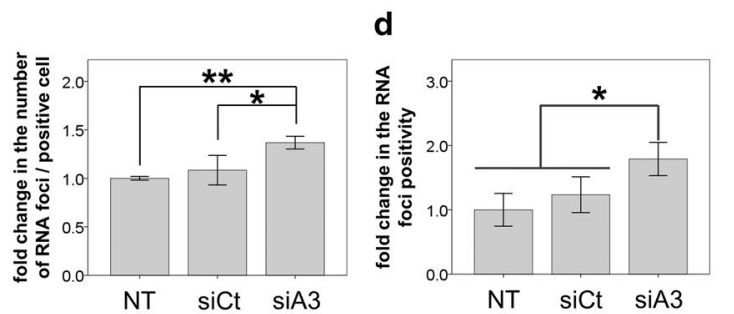
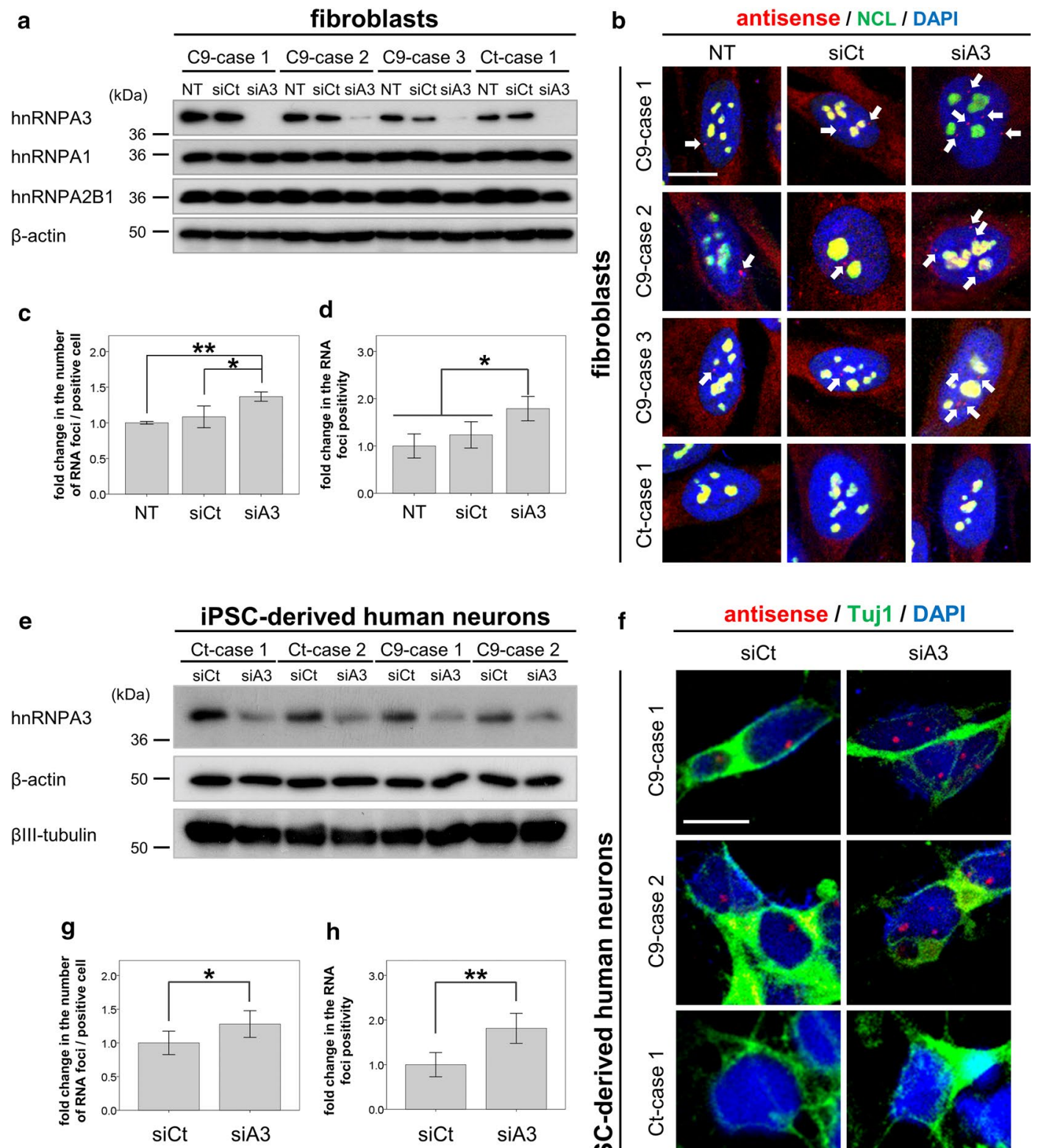

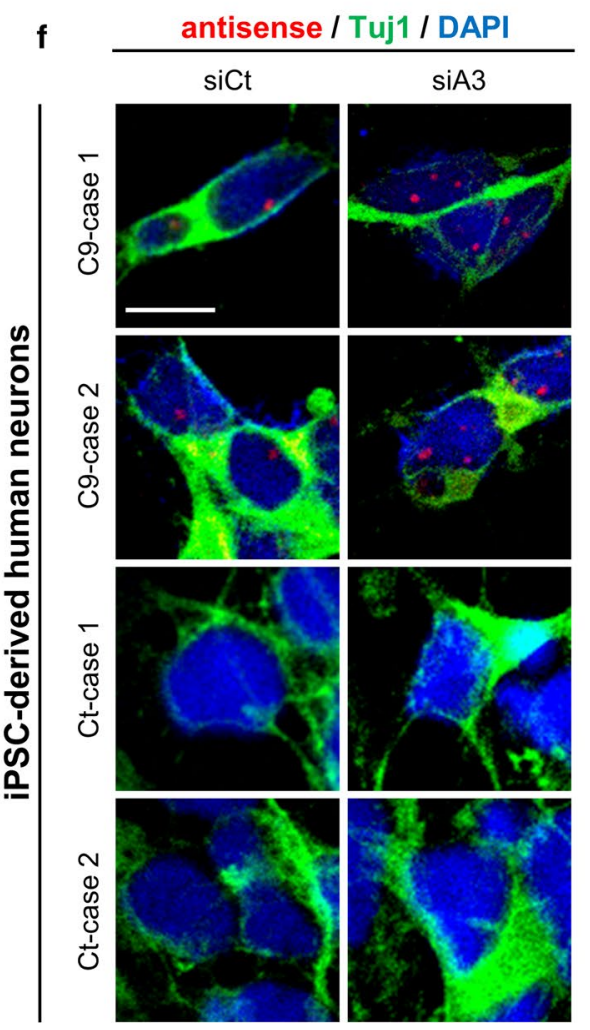

Fig. 2 Reduction of hnRNPA3 increases RNA foci number. Knockdown of hnRNPA3 increases antisense RNA foci in fibroblasts derived from C9 orf72 mutation carriers. a Western blotting with anti-hnRNPA3, hnRNPA1, and hnRNPA2B1 antibodies confirms selective and efficient siRNA-mediated knockdown of hnRNPA3. $\beta$-actin serves as a loading control. b Fluorescent in situ hybridization (FISH) of antisense repeat RNA foci in fibroblasts from 3 cases with a C9orf72 repeat extension (C9) and 1 control case (Ct). Arrows indicate Cy3-positive antisense RNA foci in the nucleus. $\mathbf{c}, \mathbf{d}$ Quantification of RNA foci number and positivity upon siRNA-mediated knockdown of hnRNPA3. $N=126-234$ cells from 3 biological replicates in each line. e Western blotting of cell lysates from iPSC-derived human neurons. Western blotting with antibodies to $\beta$-actin and $\beta$ III-tubulin confirmed selective and efficient knockdown of hnRNPA3. f FISH of antisense RNA foci in neurons from control cases (Ct) and C9orf72 carriers (C9). siCt: control siRNA, siA3: hnRNPA3-targeted siRNA. g, h Knockdown of hnRNPA3 increases antisense RNA foci number and positivity in iPSC-derived neurons from C9orf72 mutation carriers. $N=72-102$ cells from 3 biological replicates in each line. Data of 6 images in each line were used for analysis. NT non-treatment, siCt control siRNA, siA3 hnRNPA3-targeted siRNA, NCL nucleolin. All graphs are shown as mean \pm SEM. * $p<0.05$; two tailed paired $t$ test. Scale bar $10 \mu \mathrm{m}$ 

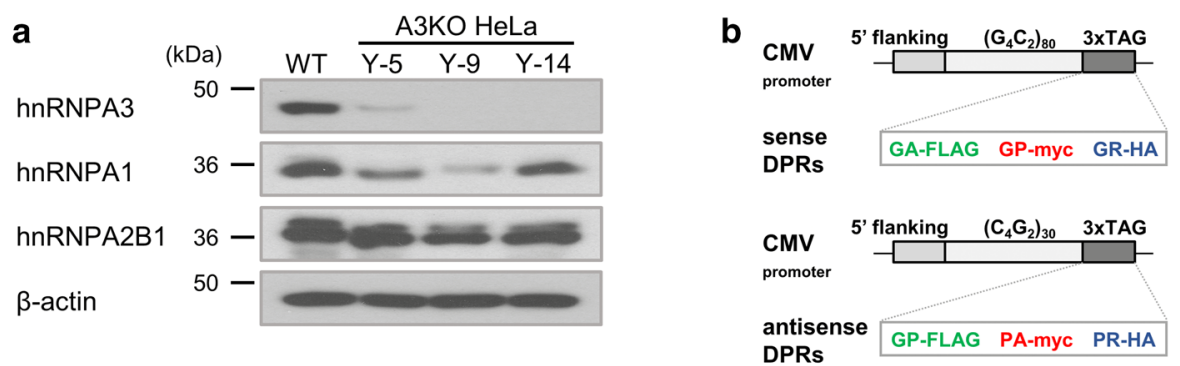

C
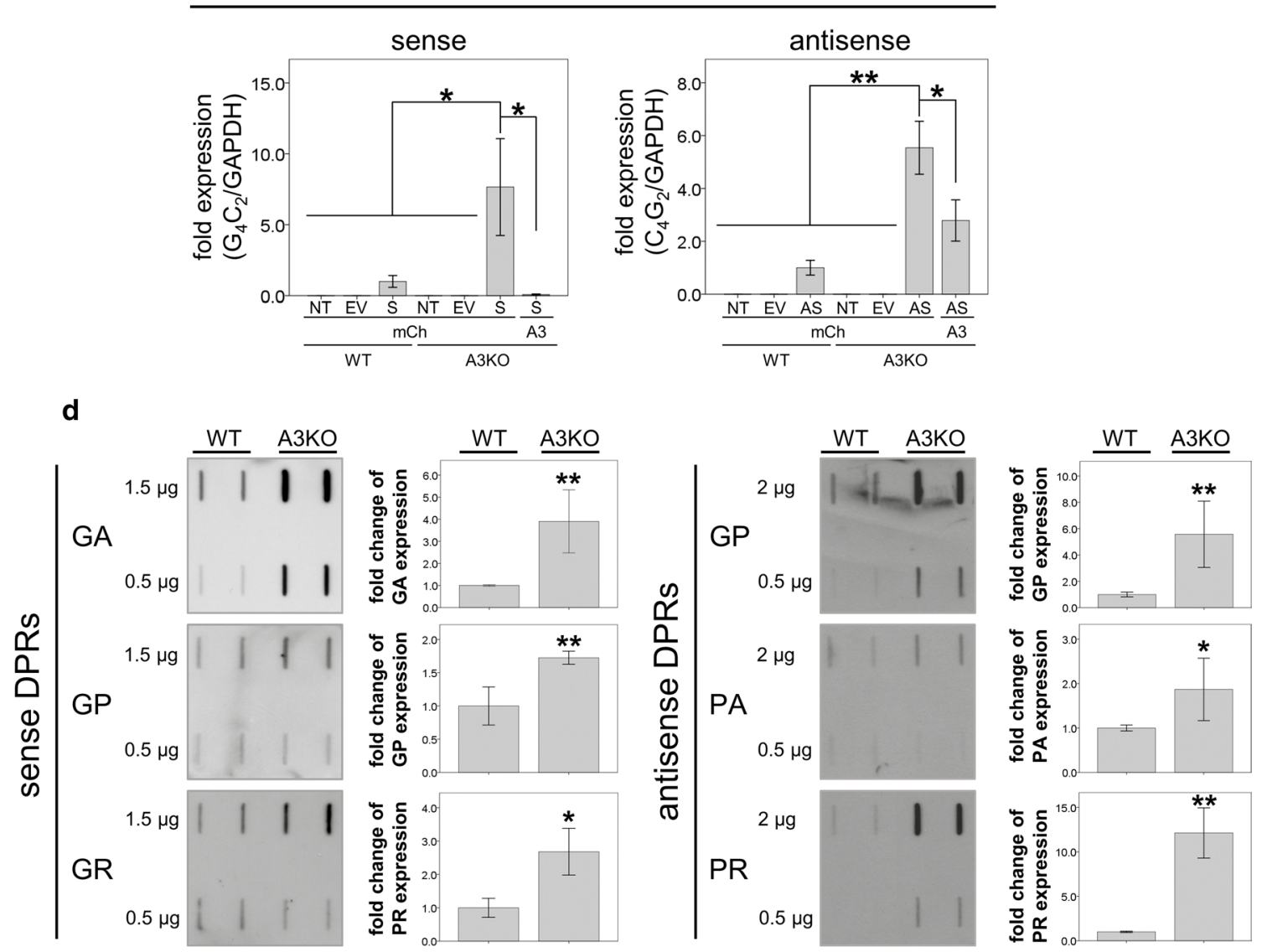

Fig. 3 Repeat RNAs and DPRs are increased upon hnRNPA3 knockout. a Western blotting confirms selective knockout of hnRNPA3 in cell lines Y-9 and Y-14. Line Y-14 was selected for all following analyses. b Schematic representation of cDNA constructs generated to express sense and antisense DPRs fused to individual tags. All graphs are shown as mean \pm SEM. ${ }^{*} p<0.05, * * p<0.01$; two tailed paired $t$ test. c Quantification of sense and antisense repeat RNA upon hnRNPA3 knockout and rescue by exogenous expression of

\section{hnRNPA3 reduction increases DNA damage in DPR-expressing HeLa cells and C9orf72 patient-derived neurons}

Since reduced hnRNPA3 enhances DSB formation [13], repeat RNA levels, and DPR expression (Figs. 2, 3), we investigated the link between hnRNPA3, DPR expression, and DNA

hnRNPA3. $N=3$ biological replicates. $N T$ non-treatment, $E V$ empty vector, $S$ sense repeat RNA, $A S$ antisense repeat RNA, $m C h$ mCherry, A3 hnRNPA3, WT HeLa wild type cells, A3KO HeLa cells with knockout of hnRNPA3. d Filter trap assay demonstrating the increase of all DPRs produced from sense and antisense repeat RNA upon hnRNPA3 knockout. $N=4$ biological replicates. All graphs are shown as mean \pm SEM. $* p<0.05, * * p<0.01$; two tailed paired t-test

damage/repair. To do so, we determined DPR-dependent DNA damage by quantifying $\gamma \mathrm{H} 2 \mathrm{AX}$ and $\mathrm{pATM}$ foci in the presence and absence of hnRNPA3. Expression of poly-GA, poly$\mathrm{GR}$, and poly-PR alone increased $\gamma \mathrm{H} 2 \mathrm{AX}$ foci formation in HeLa cells (Fig. 4a, b: $p<0.05$ or $<0.01$, see Suppl. Table 2), which was even more pronounced in the absence of hnRNPA3 (Fig. 4a, b: $p<0.05$ or $<0.01$, see Suppl. Table 2). 
a

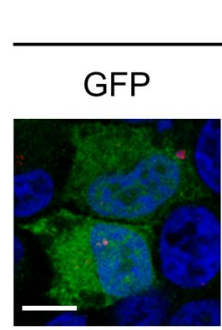

A3KO

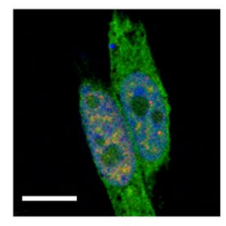

YH2AX / GFP / DAPI

GA
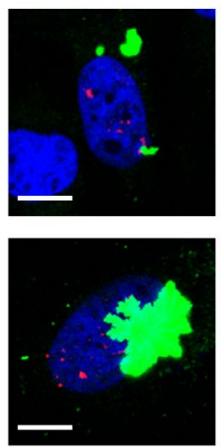

GR
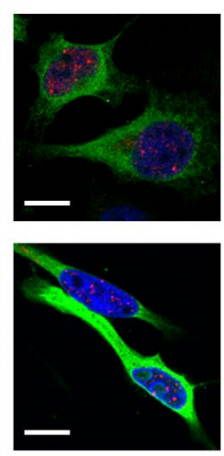

pATM / GFP / DAPI

C
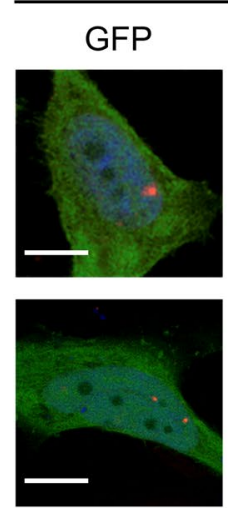

GA
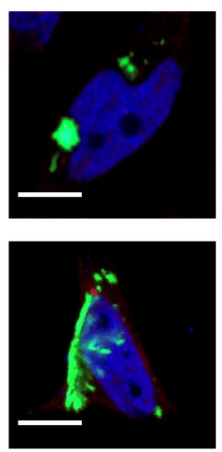

GR
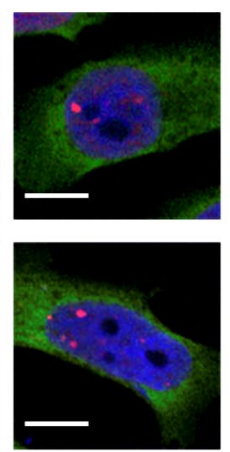
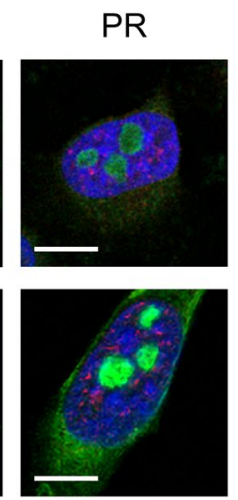

PR
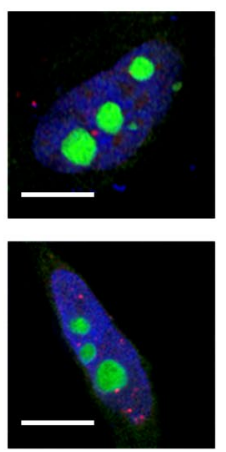

b

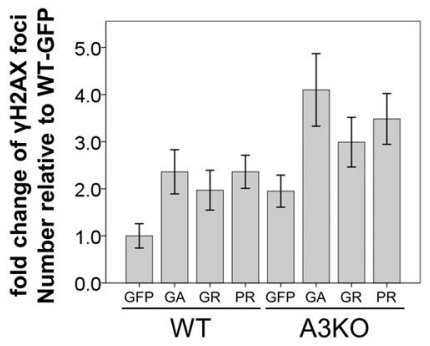

d

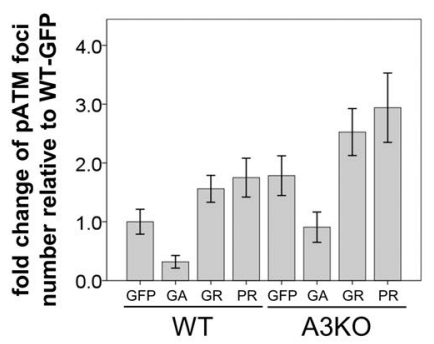

Fig. 4 hnRNPA3 knockout enhances DNA damage in DPR expressing HeLa cells. a Immunocytochemical detection of $\gamma \mathrm{H} 2 \mathrm{AX}$ foci in GFP-tagged DPR-expressing HeLa WT and A3KO HeLa cells. b Fold change of $\gamma \mathrm{H} 2 \mathrm{AX}$ foci in HeLa WT and A3KO cells expressing the indicated DPRs relative to HeLa WT cells with GFP expression. $N=47-127$ cells from 2 biological replicates. c Immunocytochemical detection of pATM foci in GFP-tagged DPR-expressing HeLa WT and A3KO HeLa cells. d Fold change of pATM foci in HeLa WT

Previously, it was reported that cells expressing expanded $\mathrm{G}_{4} \mathrm{C}_{2}$ repeat RNA or poly-GA showed decreased pATM foci in nuclei [58]; however, it is unclear if poly-GR and PR affect pATM. Therefore, we investigated the pATM foci number in cells expressing GFP or GFP-tagged DPR. Interestingly, only poly-GR and poly-PR, but not poly-GA, increased the number of pATM foci in the presence of hnRNPA3 (Fig. 4c, $\mathrm{d}: p<0.05$ or $<0.01$, see Suppl. Table 2). Furthermore, in the absence of hnRNPA3, the number of pATM foci were further increased only by poly-GR and poly-PR but not by poly-GA (Fig. 4 c, d: $p<0.05$ or $<0.01$, see Suppl. Table 2). Surprisingly, even pATM foci formation evoked by GFP expression exceeded the amount of pATM foci evoked by poly-GA (Fig. 4d: $p<0.05$, see Suppl. Table 2). These findings may suggest that poly-GA inhibits the recruitment of ATM to the site of DNA damage and thus enhances DNA damage by a mechanism different from that of arginine-containing DPRs. and A3KO cells expressing the indicated DPRs relative to HeLa WT cells with GFP expression. $N=71-263$ cells from 2 biological replicates. GFP EGFP transfected, GA EGFP-tagged poly-GA 175 repeats transfected, GR EGFP-tagged poly-GR 177 repeats transfected, PR: EGFP-tagged poly-PR 176 repeats transfected. All graphs are shown as mean \pm SEM. $* p<0.05, * * p<0.01$; one-way ANOVA and Tukey's post-hoc test. Scale bar $10 \mu \mathrm{m}$

We next asked if increased DNA damage after reduction of hnRNPA3 is also observed in human C9orf72 patientderived neurons. siRNA-mediated knockdown of hnRNPA3 significantly increased the number of $\gamma \mathrm{H} 2 \mathrm{AX}$ foci in human patient-derived neurons (Fig. 5a, b). Similarly, pATM positive foci (Fig. 5c, d) were also increased upon knockdown of hnRNPA3 in patient-derived human neurons.

\section{Low hnRNPA3 expression in hippocampal dentate gyri of C9orf72 patients is associated with enhanced DNA damage}

To investigate whether increased DNA damage also occurs in human brains and is dependent on hnRNPA 3 expression levels, we measured the correlation between the presence of $\gamma \mathrm{H} 2 \mathrm{AX}$ foci, pATM deposits, and poly-GA inclusions with nuclear hnRNPA3 expression in granular cells of the 
Fig. 5 Reduction of hnRNPA3 enhances DNA damage in human neurons. a Immunocytochemical detection of $\gamma \mathrm{H} 2 \mathrm{AX}$ foci upon siRNA-mediated knockdown of hnRNPA3 in nuclei of motor neurons derived from iPS cells with or without C9orf72 repeat expansion. b Quantification of the number of $\gamma \mathrm{H} 2 \mathrm{AX}$ signals observed in a. $N=721-1558$ cells from 2 biological replicates in each line. c Immunocytochemical detection of pATM foci upon siRNA-mediated knockdown of hnRNPA3 in the nuclei of neurons derived from iPSCs with or without $C 9$ orf72 repeat expansion. d Quantification of the number of pATM signals observed in c. $N=46-59$ cells from 2 biological replicates. $C t$ control case, $C 9$ C9orf 72 mutation carriers, siCt control siRNA, siA3 hnRNPA3-targeted siRNA. All graphs are shown as mean \pm SEM. $* p<0.05$, $* * p<0.01$; one-way ANOVA and Tukey's post-hoc test. Scale bar $10 \mu \mathrm{m}$

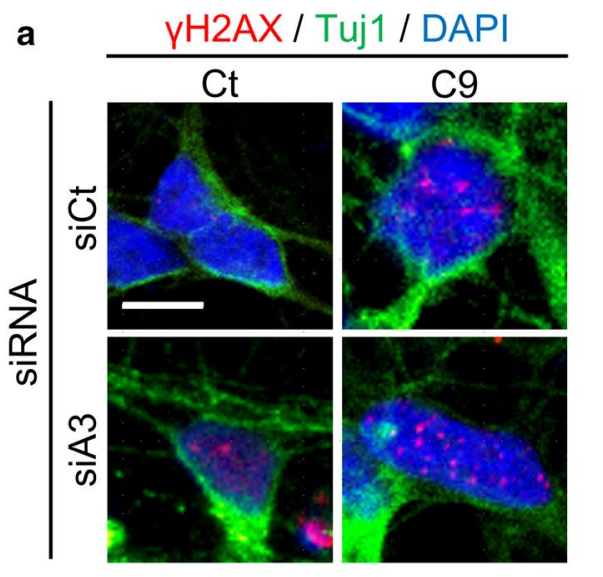

b
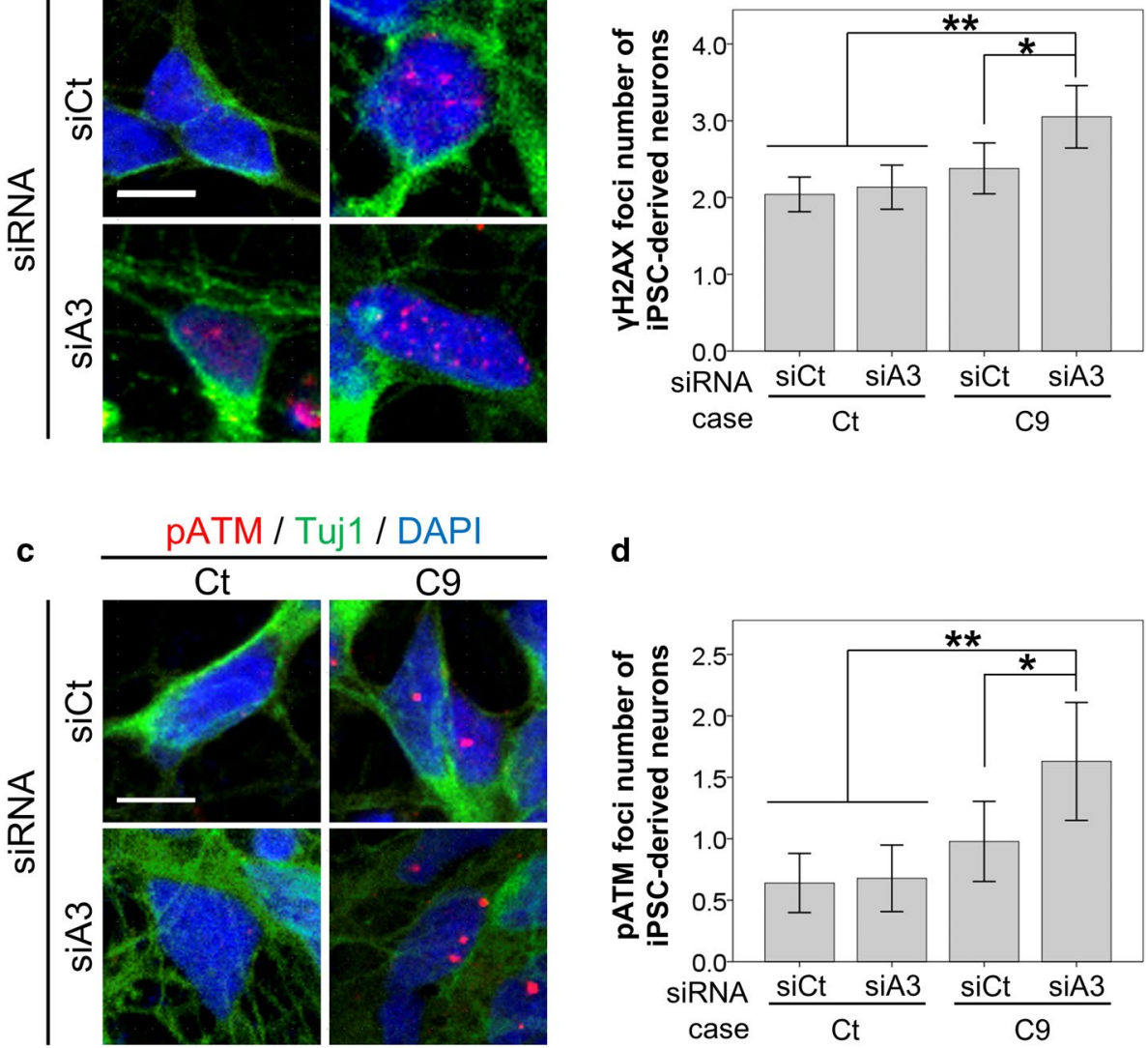

d

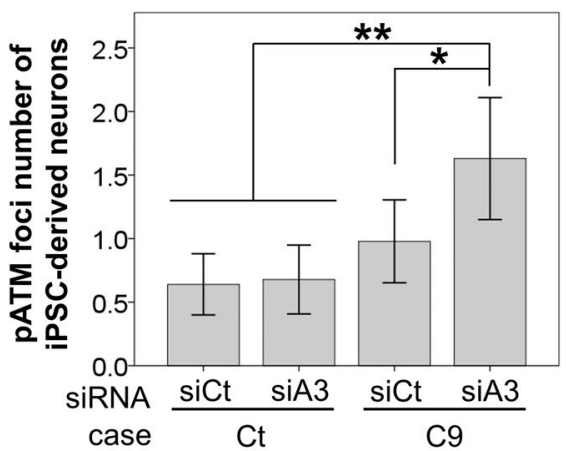

hippocampal dentate gyrus derived from patients with C9orf72 mutations by immunohistochemistry (Fig. 6a, b, Suppl. Table 3). Indeed, an increased number of $\gamma \mathrm{H} 2 \mathrm{AX}$ foci positive cells were found with lowered nuclear signal intensity of hnRNPA3 (Fig. 6a, b; Pearson's $r:-0.520, p<0.05$, Suppl. Table 3). Furthermore, the number of granular cells with poly-GA inclusions was negatively correlated with the number of granular cells with pATM foci (Fig. 6c, d. Pearson's $r$ : $-0.512, p<0.05$, Suppl. Table 3).

To rule out exacerbated RNA degradation in cases with low hnRNPA3 signals, we investigated the independent RNA binding proteins FUS and HuR (Suppl. Fig. 5). Nuclear signal intensities of both RNA proteins showed no significant correlation with the nuclear signal intensity of hnRNPA3 (Suppl. Fig. 5b, e). Moreover, nuclear signal intensities of FUS and HuR did also not correlate with $\gamma \mathrm{H} 2 \mathrm{AX}$ foci positivity (Suppl. Fig. 5c, f).

\section{Poly-GA sequesters pATM}

Notably, all C9 cases contained cytoplasmic pATM aggregates partially colocalizing with poly-GA inclusions (Fig. 7a, Suppl. Fig. 6a). On the other hand, control cases only rarely contained cytoplasmic pATM deposits, which were additionally much smaller than those in C9 cases (Fig. 7a, b, Suppl. Fig. 6b). Interestingly, hnRNPA3 aggregates also colocalize with poly-GA inclusions (Fig. 8), which is consistent with our previous study [42]. Therefore, we hypothesized that poly-GA aggregation sequesters pATM in cytoplasmic aggregates. To confirm co-aggregation of poly-GA and pATM, we performed coimmunoprecipitations in GFP-GA transfected HeLa cells (Fig. 9a). Strikingly, the anti-pATM antibody selectively co-immunoprecipitated aggregated poly-GA, which accumulated in the stacker of the gel during gel electrophoresis (Fig. 9a). In contrast, non-aggregated poly-GA was not precipitated (Fig. 9a). Poly-GR and poly-PR were not coprecipitated by the anti-pATM antibody even when using cell lysates with higher amounts of both DPRs for the coimmunoprecipitation assays (Fig. 9b; compare to Fig. 9a). Furthermore, the anti-pATM antibody did not cross-react with aggregated poly-GA (Suppl. Fig. 7) demonstrating the specificity of the co-immunoprecipitation in Fig. 9a. To further confirm that poly-GA aggregates sequester pATM in the cytoplasm, where most GA deposits occur [43], we performed co-immunoprecipitations upon from nuclear and 


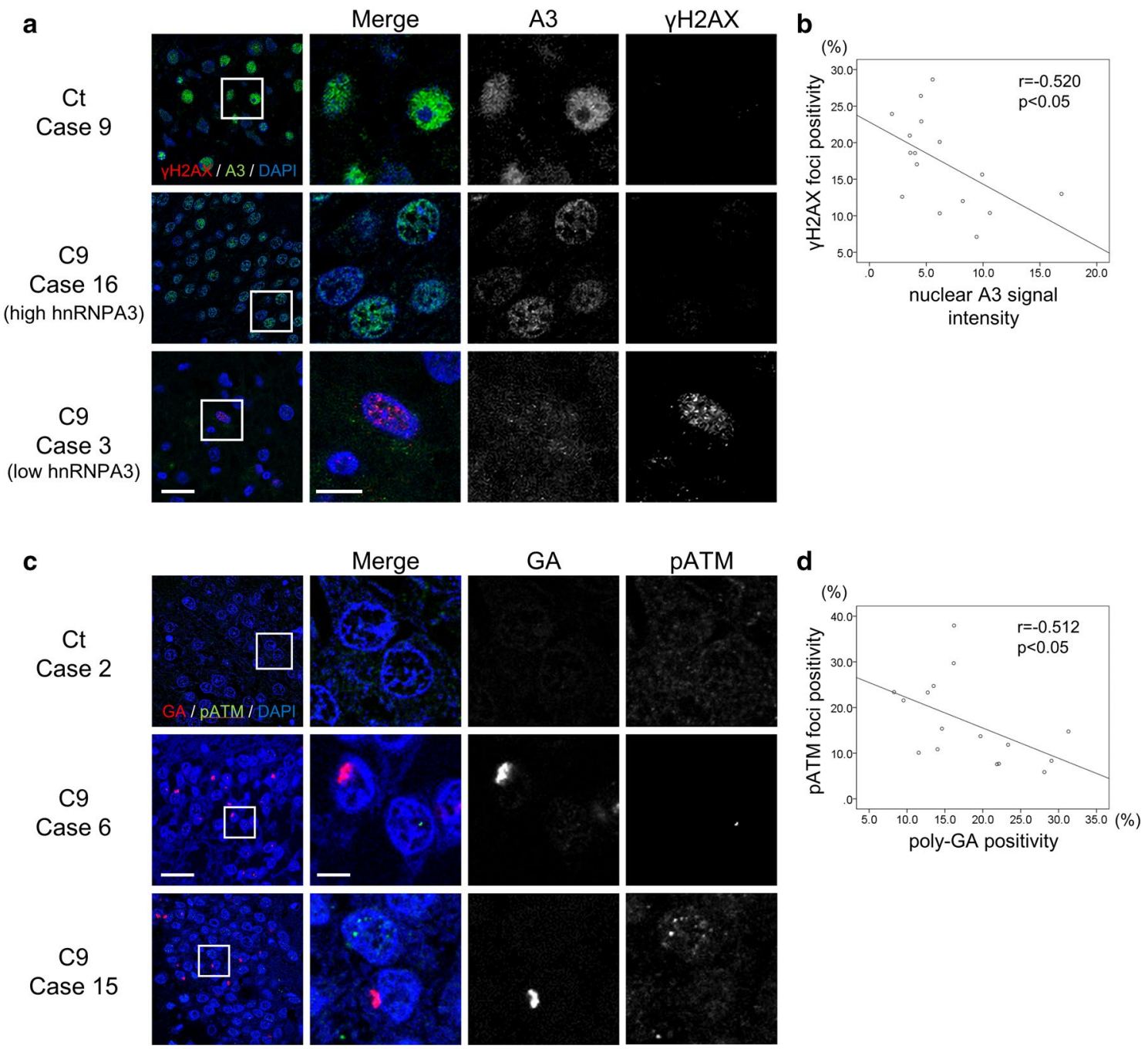

Fig. 6 Elevated DNA double strand breaks are associated with reduced hnRNPA3 and pATM foci in the dentate gyrus of $C 9$ orf72 patients. a Immunohistochemical detection of hnRNPA3 (A3) and $\gamma \mathrm{H} 2 \mathrm{AX}$ foci, a marker for double strand breaks, in granular cells of hippocampal dentate gyri of a control $(\mathrm{Ct})$ case and C9orf72 carriers (C9) with high (case 16) and low (case 3) nuclear hnRNPA3 expression. Scale bar $25 \mu \mathrm{m}$ (low magnification figures) $/ 10 \mu \mathrm{m}$ (high magnification figures). b Scatter plot of nuclear hnRNPA3 signal intensities and percentages of nuclei with $\gamma \mathrm{H} 2 \mathrm{AX}$ foci of dentate gyrus granular cells in $\mathrm{C} 9$ orf 72 carriers. Nuclear A3 intensity negatively correlates with $\gamma \mathrm{H} 2 \mathrm{AX}$ foci. Pearson's $r$ : $-0.520, p<0.05$.

cytoplasmic fractions (Suppl. Fig. 8a). Aggregated poly-GA selectively co-precipitated with pATM in the cytoplasmic fraction (Suppl. Fig. 8b), while aggregated poly-GA was not detected in the nuclear fraction and consequently no co-immunoprecipitation was observed (Suppl. Fig. 8c). Poly-GR and poly-PR did not co-precipitate with pATM in the nuclear fractions or the cytoplasmic fractions (Suppl. Fig. 8b-d). Thus, we conclude that poly-GA deposits selectively sequester pATM within the cytoplasm.
$N=16$ cases, total number of cells counted: $242-636$ cells in each case. c Immunohistochemical detection of poly-GA and pATM in granular cells of hippocampal dentate gyri of a control $(\mathrm{Ct})$ case and C9orf72 mutation carriers (C9). Poly-GA positive cells tend not to have nuclear pATM foci. Scale bar $25 \mu \mathrm{m}$ (low magnification figures) $/ 10 \mu \mathrm{m}$ (high magnification figures). d Scatter plot of percentages of dentate gyrus granular cells with poly-GA inclusions and percentages of granular cells with pATM foci in $C 9$ orf 72 carriers. Poly-GA positivity negatively correlates with pATM foci. Pearson's $r:-0.512, p<0.05 . N=16$ cases, total counted cell number: $185-407$ cells in each case

\section{Discussion}

Our study shows the functional and pathological consequences of loss of hnRNPA3 observed in C9orf72-associated neurodegeneration. First, hnRNPA 3 not only binds to sense RNA repeats but also to antisense RNA repeats (Fig. 1). Second, lowering hnRNPA3 increases sense and antisense repeat RNAs, leading to enhanced RNA foci production as well as increased DPR generation (Figs. 2, 3). 


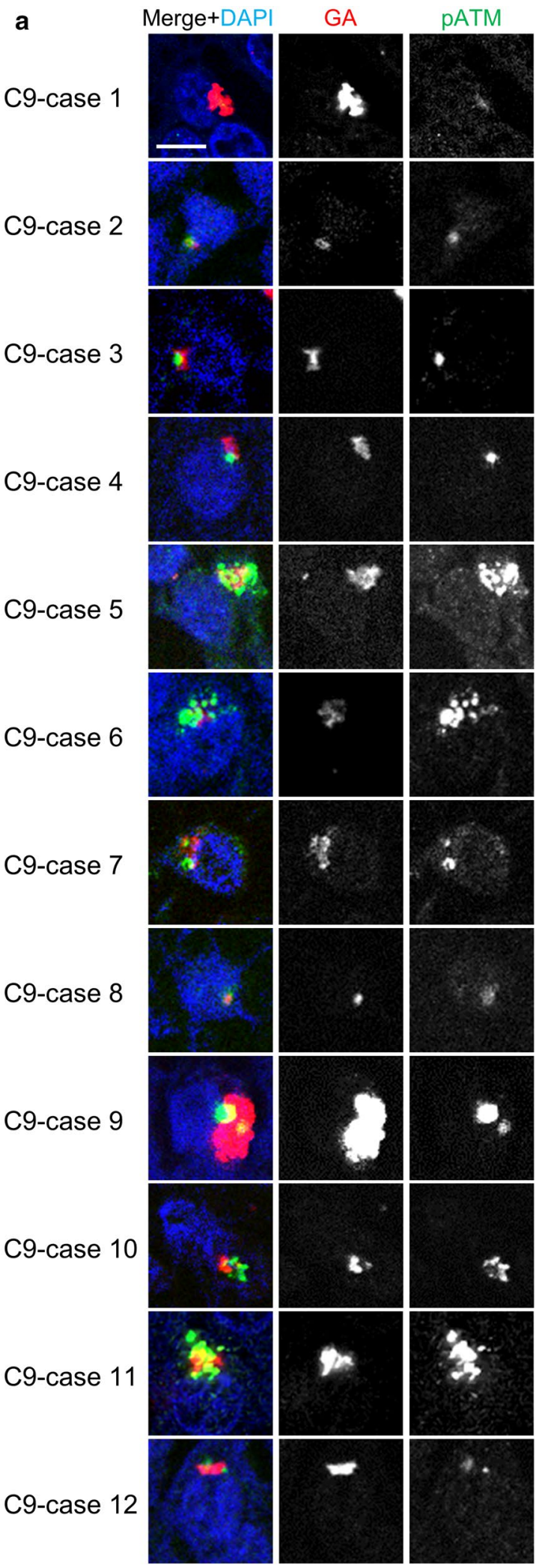

Fig. 7 Poly-GA aggregates sequester pATM in cytoplasmic aggregates. a Poly-GA aggregates partially colocalize with pATM aggregates in granular cells of hippocampal dentate gyri of C9orf72 mutation carriers. Scale bar $10 \mu \mathrm{m}$. b Percentages of dentate gyrus
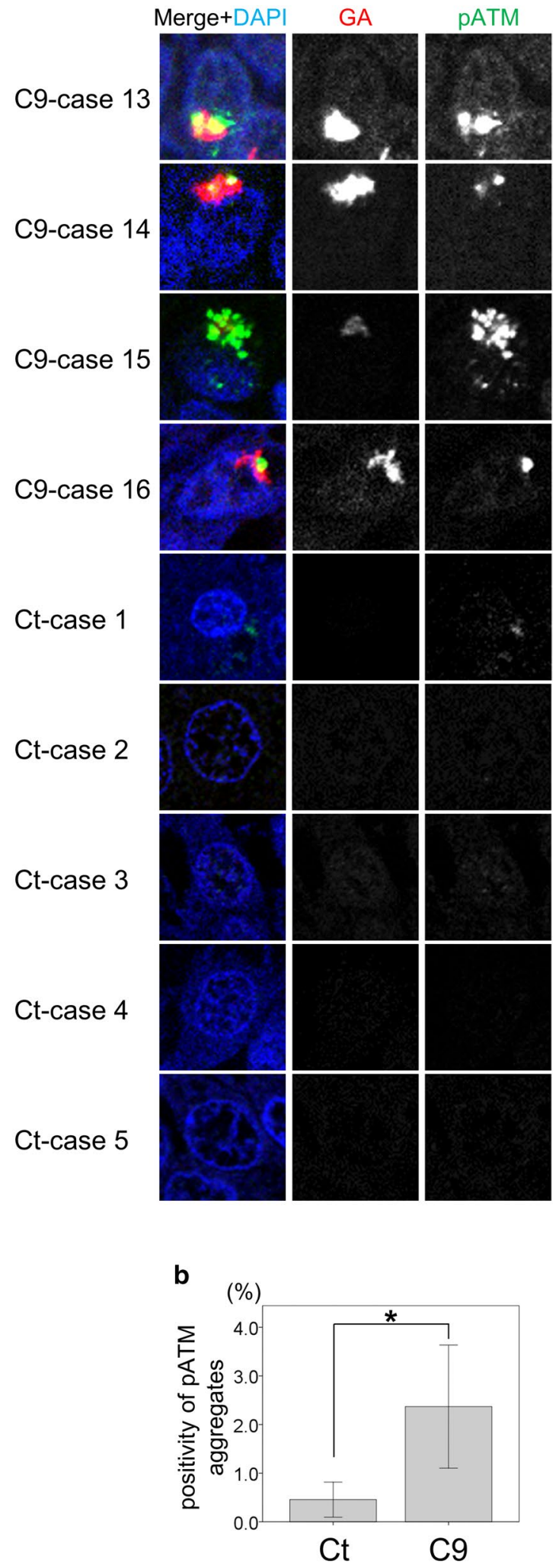

granular cells with cytoplasmic pATM aggregates (diameter $>1 \mu \mathrm{m}$ ) in control cases $(N=9)$ and $C 9$ orf72 mutation carriers $(N=16)$. $p<0.05$; two tailed paired $t$ test. $C t$ control cases, $C 9$ C9orf72 mutation carriers 
Fig. 8 Poly-GA aggregates colocalize with cytoplasmic hnRNPA3 deposits. Immunohistochemical detection of poly-GA (GA) and hnRNPA3 (A3) in granular cells of hippocampal dentate gyri of C9orf72 carriers (C9). Poly-GA aggregates partially colocalize with cytoplasmic hnRNPA3 deposits in granular cells of hippocampal dentate gyri of C9orf72 mutation carriers.

Scale bar $25 \mu \mathrm{m}$ (low magnification figures) $/ 10 \mu \mathrm{m}$ (high magnification figures)
Fig. 9 Poly-GA co-immunoprecipitation with pATM. a Aggregated poly-GA selectively co-immunoprecipitates with pATM. b To increase the sensitivity of DPR detection, cell lysates with $10 \times$ higher protein concentrations as in a were used for co-immunoprecipitation. Although aggregated polyGR and poly-PR are readily detected, only aggregated poly-GA co-immunoprecipitates with pATM. FT flow through, $N T$ non-transfected, GFP EGFP transfected, GFP-GA/GR/PR EGFP-tagged poly-GA/GR/PR 89 repeats transfected, $I g G-H C$ IgG-heavy chain, $I g G-L C$ IgGlight chain

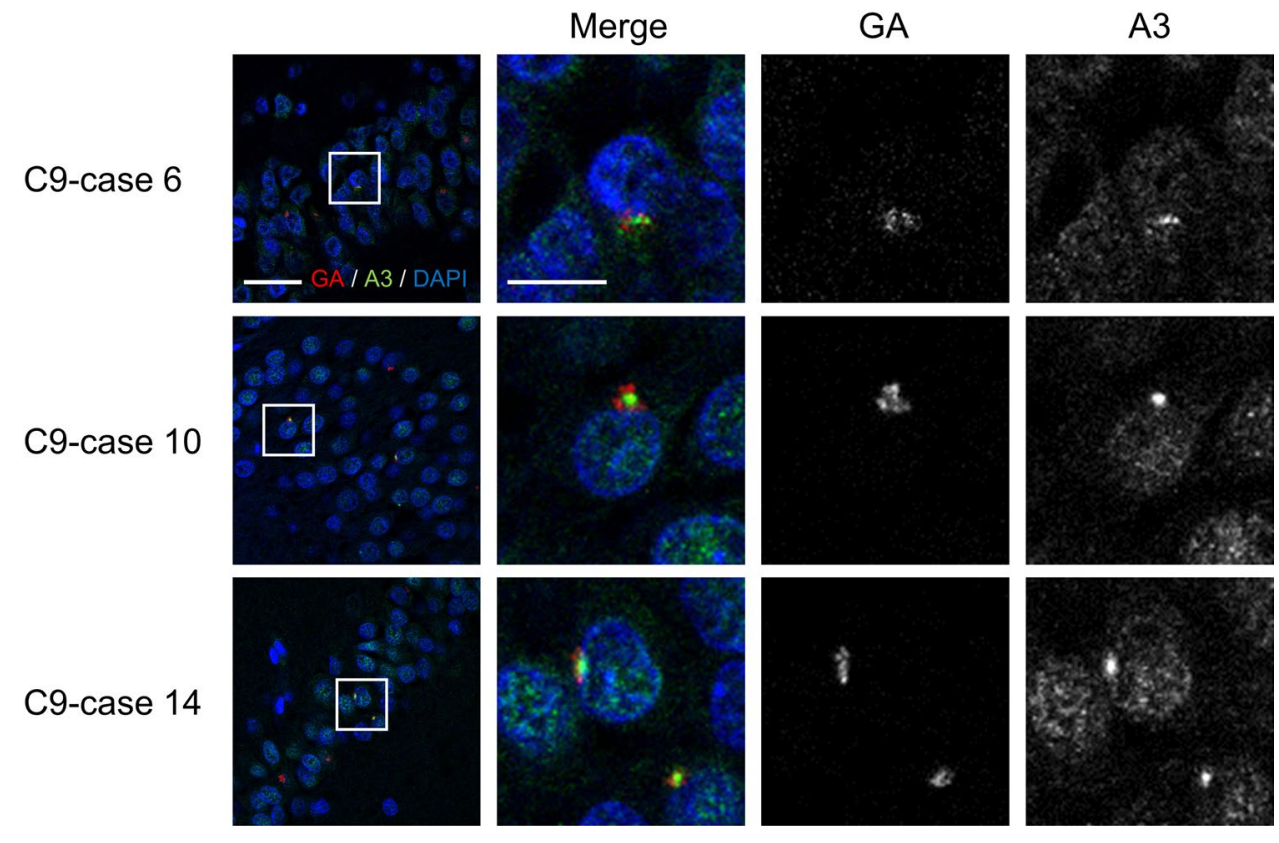

a
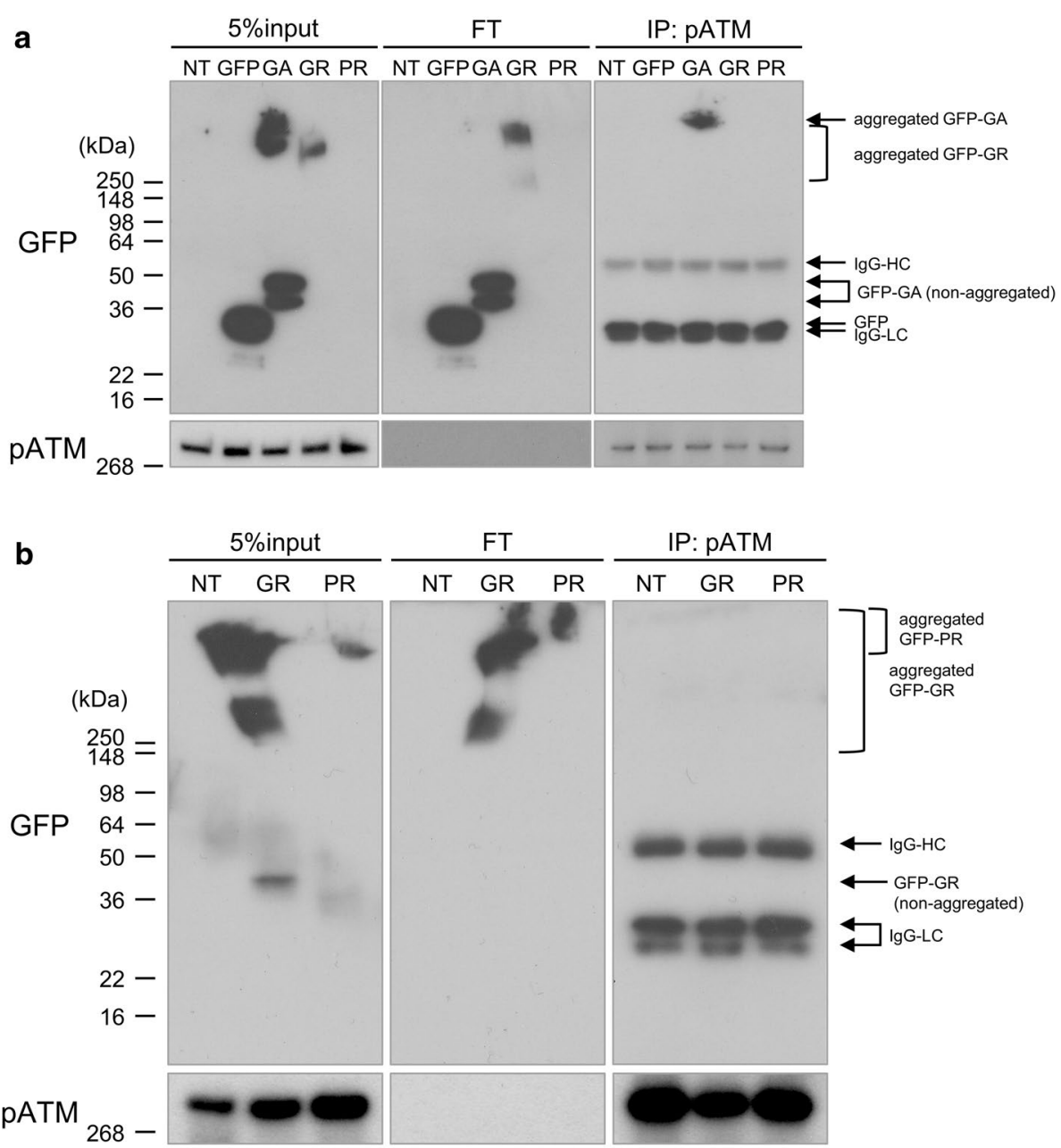


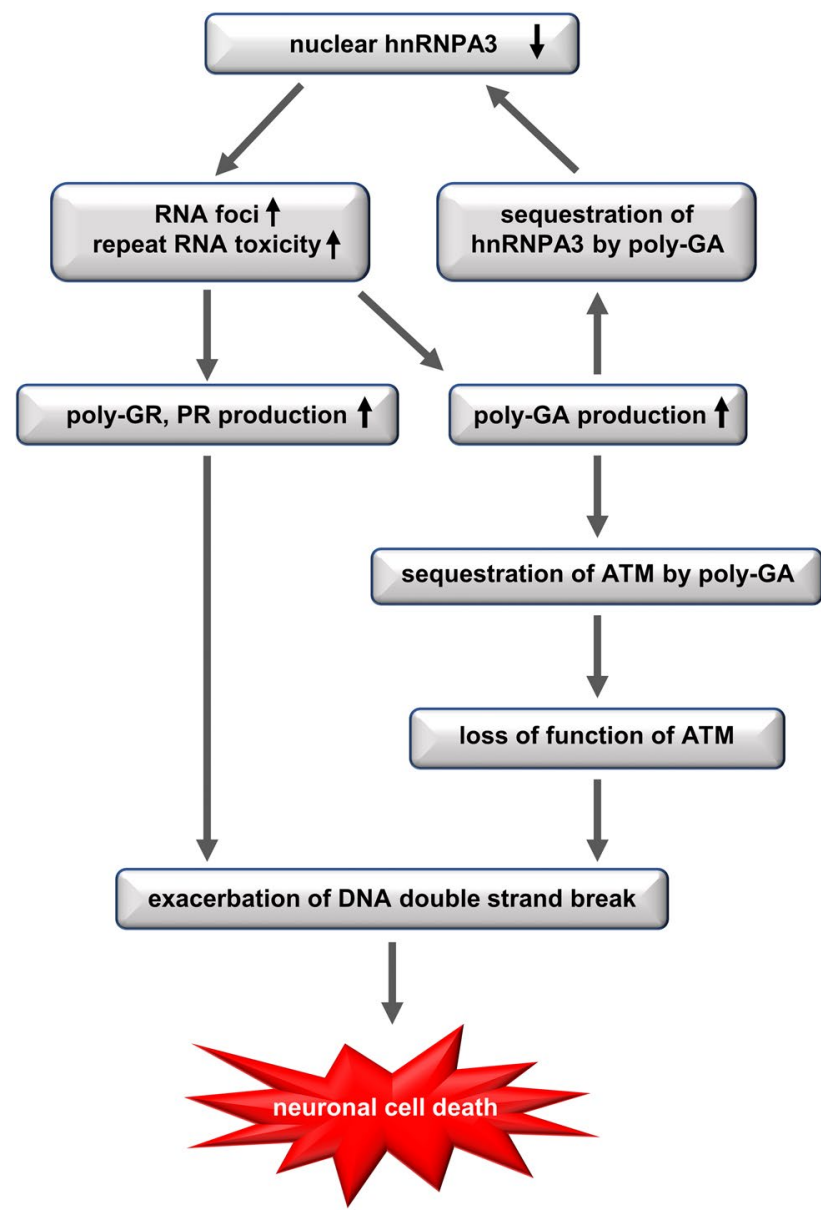

Fig. 10 Schematic model demonstrating the cellular consequences of reduced hnRNPA3

Third, reduced hnRNPA3 enhances DSB formation, which is induced by DPR (Fig. 4) and likely also by RNA foci (Fig. 5). Finally, poly-GA aggregates but no other DPRs sequester pATM within the cytoplasm and impede the recruitment of pATM to sites of DNA damage (Figs. 6, 7, 9, Suppl. Figs. 6, 8). Thus, the loss of hnRNPA3 expression likely potentiates DNA damage in C9orf72 patients' brains.

In RNA pull-down assays we demonstrate that antisense repeat RNAs bind to hnRNPA3 similarly to sense repeat RNAs (Fig. 1a). Likewise, hnRNPA1 binds to both repeat transcripts (Fig. 1b). hnRNPA1 and A3 both share very similar RNA recognition motifs (RRM) [1, 59]. However, despite similar binding efficiencies, reduced hnRNPA3 increases poly-GA expression more than reduced hnRNPA1 [42].

Reduced nuclear hnRNPA3 expression positivity correlates with higher $\gamma \mathrm{H} 2 \mathrm{AX}$ foci in dentate gyrus granular cells of patients with C9orf72 mutations (Fig. 6a, b). This is in line with our cell culture models using HeLa cells and iPSC-derived human neurons (Figs. 4, 5). These findings indicate that reduction of hnRNPA3 further promotes DSB via increased RNA foci and DPR expression. This is also consistent with the finding that reduction of hnRNPA3 itself independently promotes DSB [13]. Indeed, depletion of hnRNPA 3 increased $\gamma \mathrm{H} 2 \mathrm{AX}$ and pATM foci even in the cells with GFP only expression (Fig. 4). Thus, reduction of hnRNPA3 alone may enhance DSB, which is further increased by RNA foci and DPR expression.

Nuclear pATM foci as well as $\gamma \mathrm{H} 2 \mathrm{AX}$ foci are increased upon reduction of hnRNPA3 in cells expressing poly-GR and poly-PR (Fig. 4). In contrast, poly-GA decreased nuclear pATM foci, and, consequently, poly-GA deposition negatively correlated with nuclear pATM foci (Figs. 4c, d, 6c, d). Interestingly, cytoplasmic pATM aggregates were found in the dentate gyri of $C 9$ orf 72 patients but only rarely in control cases (Fig. 7a, b). Co-IPs revealed that pATM bound selectively to aggregated poly-GA but not to soluble polyGA (Fig. 9, Suppl. Fig. 8), which is in line with the partial co-localization of poly-GA deposits with pATM (Fig. 7a). These findings, therefore, suggest that pATM is selectively sequestered by poly-GA deposits and that sequestration impairs DSB repair in $C 9$ orf 72 cases. Interestingly, it was reported that mutant huntingtin also sequesters PATM in the cytoplasm and impairs the recruitment of pATM to sites of irradiation-induced DSB [16]. Therefore, we speculate that pATM sequestration might be a common feature in repeat expansion disorders. However, alternative pathways such as defective nucleo-cytoplasmic transport may also impair pATM recruitment. ATM exists as a dimer in the cytoplasm $[3,56]$. In response to DSB, ATM is oxidized, monomerized, and auto-phosphorylated. Subsequently, pATM binds to importin and shuttles into the nucleus [56]. DPR and C9orf72 repeat RNA are thought to impair nucleocytoplasmic transport [19, 28, 65, 66]. Therefore, nucleocytoplasmic transport dysfunction may additionally impair the recruitment of pATM to the nucleus. Walker et al. reported that repeat RNA increased $\gamma \mathrm{H} 2 \mathrm{AX}$ foci, and decreased pATM foci in the nucleus [58]. They concluded that activation of ATM was impaired by DPRs and repeat RNA. We now demonstrate that DPRs may affect ATM activation via differential individual mechanisms, i.e., poly-GA, but not poly-GR or poly-PR, sequesters ATM in cytoplasmic deposits. We have not further investigated how poly-GR and poly-PR enhance DSB without sequestration of pATM; however, there are some reports that show an association of poly-GR and poly-PR with DNA damage repair. LopezGonzalez et al. reported that poly-GR binds to mitochondrial ribosomal proteins and leads to mitochondrial dysfunction, oxidative stress, and DNA damage [32]. Others reported that poly-GR and poly-PR change the intranuclear distribution of NPM1, which is protective against DNA damage [15, 54, 62]. Thus, each neurotoxic DPR may affect DNA damage in an individual way. On the other hand, the prevalence of polyGR and poly-PR depositions is much lower than poly-GA deposits in human brains [51]. Poly-GA may, therefore, be 
the most relevant DPR in the pathological cascade of DNA damage in human brains.

Finally, we have not fully defined how H2AX is phosphorylated in the absence of pATM recruitment. After pATM is recruited to sites of DSB, pATM normally phosphorylates $\mathrm{H} 2 \mathrm{AX}$ and converts it to $\gamma \mathrm{H} 2 \mathrm{AX}[10]$. Thus, it is rather surprising that poly-GA increases $\gamma \mathrm{H} 2 \mathrm{AX}$ while decreasing pATM. We speculate that under these conditions $\gamma \mathrm{H} 2 \mathrm{AX}$ is phosphorylated by the poly-GA induced DNA-PK, which is a known H2AX kinase [53]. Therefore, DNA-PK may be able to phosphorylate $\mathrm{H} 2 \mathrm{AX}$ at the sites of DSB, though precipitation of pATM into poly-GA aggregates may nevertheless cause a loss of function.

Taken together, we conclude that reduced hnRNPA3 enhances DNA damage (1) by increasing $\left(\mathrm{G}_{4} \mathrm{C}_{2}\right) n$ and $\left(\mathrm{C}_{4} \mathrm{G}_{2}\right) n$ expressions and foci formation (2) by increasing DPR expression, and (3) by impairment of ATM-mediated DNA damage repair through the sequestration of pATM by poly-GA (Fig. 10).

Acknowledgements This work was supported by the NOMIS foundation (to C.H., D.E. and A.H.), the Munich Cluster of Systems Neurology (SyNergy) (to C.H and D.E.) and the Helmholtz Virtual Institute "RNA dysmetabolism in ALS and FTD (VH-VI-510)" (to C.H. and A.H). KM is supported by grants from JSPS KAKENHI (JP16H05379, JP17H05091, JP18K19515), AMED (JP18ek0109316), Mochida Memorial Foundation, Takeda Science Foundation and SENSHIN Medical Research Foundation, AH is supported by the Hermann und Lilly Schilling-Stiftung für medizinische Forschung im Stifterverband. DE was supported by the European Community's Health Seventh Framework Programme under grant agreement 617198 [DPR-MODELS]. AS and MW were supported by the Swiss ALS Foundation. We were grateful to Daisuke Ito (Keio University School of Medicine, Department of Neurology) for providing Lenti-Hb9-GFP plasmid, Xenia Lojewski and Hannes Glass for the help of the generation of iPSCs, and Jane Hettinger for carefully proofreading the manuscript.

\section{Compliance with ethical standards}

Conflict of interest $\mathrm{CH}$ collaborates with Denali Therapeutics on a topic not related to C9orf72, participated on one advisory board meeting of Biogen, and received a speaker honorarium from Novartis and Roche. All other authors declare that they have no conflict of interest.

Ethical approval All procedures performed in this study involving human participants were in accordance with the ethical standards of the institutional research committee and with the 1964 Helsinki declaration and its later amendments or comparable ethical standards.

Informed consent Informed consent was obtained from all individual participants or participants' families included in this study.

Open Access This article is distributed under the terms of the Creative Commons Attribution 4.0 International License (http://creativeco mmons.org/licenses/by/4.0/), which permits unrestricted use, distribution, and reproduction in any medium, provided you give appropriate credit to the original author(s) and the source, provide a link to the Creative Commons license, and indicate if changes were made.

\section{References}

1. Akindahunsi AA, Bandiera A, Manzini G (2005) Vertebrate 2xRBD hnRNP proteins: a comparative analysis of genome, mRNA and protein sequences. Comput Biol Chem 29:13-23. https://doi.org/10.1016/j.compbiolchem.2004.11.002

2. Ash PE, Bieniek KF, Gendron TF, Caulfield T, Lin WL, Dejesus-Hernandez M et al (2013) Unconventional translation of C9ORF72 GGGGCC expansion generates insoluble polypeptides specific to c9FTD/ALS. Neuron 77:639-646. https://doi. org/10.1016/j.neuron.2013.02.004

3. Bakkenist CJ, Kastan MB (2003) DNA damage activates ATM through intermolecular autophosphorylation and dimer dissociation. Nature 421:499-506. https://doi.org/10.1038/nature01368

4. Barker S, Weinfeld M, Zheng J, Li L, Murray D (2005) Identification of mammalian proteins cross-linked to DNA by ionizing radiation. J Biol Chem 280:33826-33838. https://doi.org/10.1074/ jbc.M502477200

5. Barroso-Gonzalez J, Auclair S, Luan S, Thomas L, Atkins KM, Aslan JE et al (2016) PACS-2 mediates the ATM and NF-kappaBdependent induction of anti-apoptotic Bcl-xL in response to DNA damage. Cell Death Differ 23:1448-1457. https://doi.org/10.1038/ cdd.2016.23

6. Bender A, Krishnan KJ, Morris CM, Taylor GA, Reeve AK, Perry RH et al (2006) High levels of mitochondrial DNA deletions in substantia nigra neurons in aging and Parkinson disease. Nat Genet 38:515-517. https://doi.org/10.1038/ng1769

7. Bennion Callister J, Ryan S, Sim J, Rollinson S, Pickering-Brown SM (2016) Modelling C9orf72 dipeptide repeat proteins of a physiologically relevant size. Hum Mol Genet 25:5069-5082. https:// doi.org/10.1093/hmg/ddw327

8. Boeynaems S, Gitler AD (2018) Pour Some Sugar on TDP(43). Mol Cell 71:649-651. https://doi.org/10.1016/j.molce 1.2018.08.032

9. Bradley-Whitman MA, Timmons MD, Beckett TL, Murphy MP, Lynn BC, Lovell MA (2014) Nucleic acid oxidation: an early feature of Alzheimer's disease. J Neurochem 128:294-304. https ://doi.org/10.1111/jnc.12444

10. Burma S, Chen BP, Murphy M, Kurimasa A, Chen DJ (2001) ATM phosphorylates histone H2AX in response to DNA double-strand breaks. J Biol Chem 276:42462-42467. https://doi. org/10.1074/jbc.C100466200

11. Camins A, Pizarro JG, Alvira D, Gutierrez-Cuesta J, de la Torre $\mathrm{AV}$, Folch J et al (2010) Activation of ataxia telangiectasia muted under experimental models and human Parkinson's disease. Cell Mol Life Sci 67:3865-3882. https://doi.org/10.1007/s0001 8-010-0408-5

12. Cloutier A, Shkreta L, Toutant J, Durand M, Thibault P, Chabot B (2018) hnRNP A1/A2 and Sam68 collaborate with SRSF10 to control the alternative splicing response to oxaliplatin-mediated DNA damage. Sci Rep 8:2206. https://doi.org/10.1038/s4159 8-018-20360-x

13. Comegna M, Succoio M, Napolitano M, Vitale M, D’Ambrosio C, Scaloni A et al (2014) Identification of miR-494 direct targets involved in senescence of human diploid fibroblasts. FASEB J 28:3720-3733. https://doi.org/10.1096/fj.13-239129

14. DeJesus-Hernandez M, Mackenzie IR, Boeve BF, Boxer AL, Baker M, Rutherford NJ et al (2011) Expanded GGGGCC hexanucleotide repeat in noncoding region of C9ORF72 causes chromosome 9p-linked FTD and ALS. Neuron 72:245-256. https:// doi.org/10.1016/j.neuron.2011.09.011

15. Farg MA, Konopka A, Ying Soo K, Ito D, Atkin JD (2017) The DNA damage response (DDR) is induced by the C9orf72 repeat expansion in amyotrophic lateral sclerosis. Hum Mol Genet 26:2882-2896. https://doi.org/10.1093/hmg/ddx170 
16. Ferlazzo ML, Sonzogni L, Granzotto A, Bodgi L, Lartin O, Devic $\mathrm{C}$ et al (2014) Mutations of the Huntington's disease protein impact on the ATM-dependent signaling and repair pathways of the radiation-induced DNA double-strand breaks: corrective effect of statins and bisphosphonates. Mol Neurobiol 49:1200-1211. https://doi.org/10.1007/s12035-013-8591-7

17. Fifita JA, Zhang KY, Galper J, Williams KL, McCann EP, Hogan AL et al (2017) Genetic and pathological assessment of hnRNPA1, hnRNPA2/B1, and hnRNPA3 in familial and sporadic amyotrophic lateral sclerosis. Neurodegener Dis 17:304-312. https://doi.org/10.1159/000481258

18. Fratta P, Mizielinska S, Nicoll AJ, Zloh M, Fisher EM, Parkinson $\mathrm{G}$ et al (2012) C9orf72 hexanucleotide repeat associated with amyotrophic lateral sclerosis and frontotemporal dementia forms RNA G-quadruplexes. Sci Rep 2:1016. https://doi.org/10.1038/ srep01016

19. Freibaum BD, Lu Y, Lopez-Gonzalez R, Kim NC, Almeida S, Lee $\mathrm{KH}$ et al (2015) GGGGCC repeat expansion in C9orf72 compromises nucleocytoplasmic transport. Nature 525:129-133. https:// doi.org/10.1038/nature14974

20. Gijselinck I, Van Langenhove T, van der Zee J, Sleegers K, Philtjens S, Kleinberger G et al (2012) A C9orf72 promoter repeat expansion in a Flanders-Belgian cohort with disorders of the frontotemporal lobar degeneration-amyotrophic lateral sclerosis spectrum: a gene identification study. Lancet Neurol 11:54-65. https ://doi.org/10.1016/s1474-4422(11)70261-7

21. Giuliano P, De Cristofaro T, Affaitati A, Pizzulo GM, Feliciello A, Criscuolo C et al (2003) DNA damage induced by polyglutamineexpanded proteins. Hum Mol Genet 12:2301-2309. https://doi. org $/ 10.1093 / \mathrm{hmg} / \mathrm{ddg} 242$

22. Glass H, Pal A, Reinhardt P, Sterneckert J, Wegner F, Storch A et al (2018) Defective mitochondrial and lysosomal trafficking in chorea-acanthocytosis is independent of Src-kinase signaling. Mol Cell Neurosci 92:137-148. https://doi.org/10.1016/j. men.2018.08.002

23. Haeusler AR, Donnelly CJ, Periz G, Simko EA, Shaw PG, Kim MS et al (2014) C9orf72 nucleotide repeat structures initiate molecular cascades of disease. Nature 507:195-200. https://doi. org/10.1038/nature13124

24. Haley B, Paunesku T, Protic M, Woloschak GE (2009) Response of heterogeneous ribonuclear proteins (hnRNP) to ionising radiation and their involvement in DNA damage repair. Int J Radiat Biol 85:643-655. https://doi.org/10.1080/09553000903009548

25. Horton TM, Graham BH, Corral-Debrinski M, Shoffner JM, Kaufman AE, Beal MF et al (1995) Marked increase in mitochondrial DNA deletion levels in the cerebral cortex of Huntington's disease patients. Neurology 45:1879-1883

26. Japtok J, Lojewski X, Naumann M, Klingenstein M, Reinhardt P, Sterneckert J et al (2015) Stepwise acquirement of hallmark neuropathology in FUS-ALS iPSC models depends on mutation type and neuronal aging. Neurobiol Dis 82:420-429. https://doi. org/10.1016/j.nbd.2015.07.017

27. Kanekura K, Yagi T, Cammack AJ, Mahadevan J, Kuroda M, Harms MB et al (2016) Poly-dipeptides encoded by the C9ORF72 repeats block global protein translation. Hum Mol Genet. https:// doi.org/10.1093/hmg/ddw052

28. Khosravi B, Hartmann H, May S, Mohl C, Ederle H, Michaelsen $M$ et al (2017) Cytoplasmic poly-GA aggregates impair nuclear import of TDP-43 in C9orf72 ALS/FTLD. Hum Mol Genet 26:790-800. https://doi.org/10.1093/hmg/ddw432

29. Kwon I, Xiang S, Kato M, Wu L, Theodoropoulos P, Wang T et al (2014) Poly-dipeptides encoded by the C9orf72 repeats bind nucleoli, impede RNA biogenesis, and kill cells. Science 345:1139-1145. https://doi.org/10.1126/science.1254917

30. Lee SK, Jurata LW, Funahashi J, Ruiz EC, Pfaff SL (2004) Analysis of embryonic motoneuron gene regulation: derepression of general activators function in concert with enhancer factors. Development 131:3295-3306. https://doi.org/10.1242/dev.01179

31. Li H, Wyman T, Yu ZX, Li SH, Li XJ (2003) Abnormal association of mutant huntingtin with synaptic vesicles inhibits glutamate release. Hum Mol Genet 12:2021-2030. https://doi.org/10.1093/ $\mathrm{hmg} / \mathrm{ddg} 218$

32. Lopez-Gonzalez R, Lu Y, Gendron TF, Karydas A, Tran H, Yang D et al (2016) Poly(GR) in C9ORF72-related ALS/FTD compromises mitochondrial function and increases oxidative stress and DNA damage in iPSC-derived motor neurons. Neuron 92:383391. https://doi.org/10.1016/j.neuron.2016.09.015

33. Loughlin FE, Lukavsky PJ, Kazeeva T, Reber S, Hock EM, Colombo M et al (2019) The solution structure of FUS bound to RNA reveals a bipartite mode of RNA recognition with both sequence and shape specificity. Mol Cell 73(490-504):e496. https ://doi.org/10.1016/j.molcel.2018.11.012

34. Lovell MA, Markesbery WR (2007) Oxidative DNA damage in mild cognitive impairment and late-stage Alzheimer's disease. Nucleic Acids Res 35:7497-7504. https://doi.org/10.1093/nar/ gkm821

35. Mackenzie IR, Arzberger T, Kremmer E, Troost D, Lorenzl $\mathrm{S}$, Mori K et al (2013) Dipeptide repeat protein pathology in C9ORF72 mutation cases: clinico-pathological correlations. Acta Neuropathol 126:859-879. https://doi.org/10.1007/s0040 1-013-1181-y

36. McGurk L, Gomes E, Guo L, Mojsilovic-Petrovic J, Tran V, Kalb RG et al (2018) Poly(ADP-ribose) prevents pathological phase separation of TDP-43 by promoting liquid demixing and stress granule localization. Mol Cell 71(703-717):e709. https://doi. org/10.1016/j.molcel.2018.07.002

37. Merlo D, Mollinari C, Racaniello M, Garaci E, Cardinale A (2016) DNA double strand breaks: a common theme in neurodegenerative diseases. Curr Alzheimer Res 13:1208-1218. https:// doi.org/10.2174/15672050136661604011

38. Mizielinska S, Ridler CE, Balendra R, Thoeng A, Woodling NS, Grasser FA et al (2017) Bidirectional nucleolar dysfunction in C9orf72 frontotemporal lobar degeneration. Acta Neuropathol Commun 5:29. https://doi.org/10.1186/s40478-017-0432-x

39. Mizielinska SL, Norona FE, Clayton EL, Ridler CE, Fratta P, Isaacs AM (2013) C9orf72 frontotemporal lobar degeneration is characterised by frequent neuronal sense and antisense RNA foci. Acta Neuropathol 126:845-857. https://doi.org/10.1007/s0040 $1-013-1200-z$

40. Mori K, Arzberger T, Grasser FA, Gijselinck I, May S, Rentzsch $\mathrm{K}$ et al (2013) Bidirectional transcripts of the expanded C9orf72 hexanucleotide repeat are translated into aggregating dipeptide repeat proteins. Acta Neuropathol 126:881-893. https://doi. org/10.1007/s00401-013-1189-3

41. Mori K, Lammich S, Mackenzie IR, Forne I, Zilow S, Kretzschmar $\mathrm{H}$ et al (2013) hnRNP A3 binds to GGGGCC repeats and is a constituent of p62-positive/TDP43-negative inclusions in the hippocampus of patients with C9orf72 mutations. Acta Neuropathol 125:413-423. https://doi.org/10.1007/s00401-013-1088-7

42. Mori K, Nihei Y, Arzberger T, Zhou Q, Mackenzie IR, Hermann A et al (2016) Reduced hnRNPA3 increases C9orf72 repeat RNA levels and dipeptide-repeat protein deposition. EMBO Rep 17:1314-1325. https://doi.org/10.15252/embr.201541724

43. Mori K, Weng SM, Arzberger T, May S, Rentzsch K, Kremmer E et al (2013) The C9orf72 GGGGCC repeat is translated into aggregating dipeptide-repeat proteins in FTLD/ALS. Science 339:1335-1338. https://doi.org/10.1126/science.1232927

44. Naumann M, Pal A, Goswami A, Lojewski X, Japtok J, Vehlow A et al (2018) Impaired DNA damage response signaling by FUSNLS mutations leads to neurodegeneration and FUS aggregate formation. Nat Commun 9:335. https://doi.org/10.1038/s4146 7-017-02299-1 
45. Nihei Y, Ito D, Okada Y, Akamatsu W, Yagi T, Yoshizaki T et al (2013) Enhanced aggregation of androgen receptor in induced pluripotent stem cell-derived neurons from spinal and bulbar muscular atrophy. J Biol Chem 288:8043-8052. https://doi. org/10.1074/jbc.M112.408211

46. Nordin A, Akimoto C, Wuolikainen A, Alstermark H, Forsberg $\mathrm{K}$, Baumann $\mathrm{P}$ et al (2017) Sequence variations in C9orf72 downstream of the hexanucleotide repeat region and its effect on repeatprimed PCR interpretation: a large multinational screening study. Amyotroph Lateral Scler Frontotemporal Degener 18:256-264. https://doi.org/10.1080/21678421.2016.1262423

47. O'Driscoll M, Jeggo PA (2006) The role of double-strand break repair - insights from human genetics. Nat Rev Genet 7:45-54. https://doi.org/10.1038/nrg1746

48. Patel A, Lee HO, Jawerth L, Maharana S, Jahnel M, Hein MY et al (2015) A liquid-to-solid phase transition of the ALS protein FUS accelerated by disease mutation. Cell 162:1066-1077. https ://doi.org/10.1016/j.cell.2015.07.047

49. Ran FA, Hsu PD, Wright J, Agarwala V, Scott DA, Zhang F (2013) Genome engineering using the CRISPR-Cas9 system. Nat Protoc 8:2281-2308. https://doi.org/10.1038/nprot.2013.143

50. Renton AE, Majounie E, Waite A, Simon-Sanchez J, Rollinson S, Gibbs JR et al (2011) A hexanucleotide repeat expansion in C9ORF72 is the cause of chromosome 9p21-linked ALS-FTD. Neuron 72:257-268. https://doi.org/10.1016/j.neuron.2011.09.010

51. Schludi MH, May S, Grasser FA, Rentzsch K, Kremmer E, Kupper C et al (2015) Distribution of dipeptide repeat proteins in cellular models and C9orf72 mutation cases suggests link to transcriptional silencing. Acta Neuropathol 130:537-555. https://doi. org/10.1007/s00401-015-1450-z

52. Sivadasan R, Hornburg D, Drepper C, Frank N, Jablonka S, Hansel A et al (2016) C9ORF72 interaction with cofilin modulates actin dynamics in motor neurons. Nat Neurosci. https://doi. org/10.1038/nn.4407

53. Stiff T, O'Driscoll M, Rief N, Iwabuchi K, Lobrich M, Jeggo PA (2004) ATM and DNA-PK function redundantly to phosphorylate $\mathrm{H} 2 \mathrm{AX}$ after exposure to ionizing radiation. Cancer Res 64:2390-2396

54. Tao Z, Wang H, Xia Q, Li K, Li K, Jiang X et al (2015) Nucleolar stress and impaired stress granule formation contribute to C9orf72 RAN translation-induced cytotoxicity. Hum Mol Genet 24:24262441. https://doi.org/10.1093/hmg/ddv005

55. Tchurikov NA, Kretova OV, Fedoseeva DM, Sosin DV, Grachev SA, Serebraykova MV et al (2013) DNA double-strand breaks coupled with PARP1 and HNRNPA2B1 binding sites flank coordinately expressed domains in human chromosomes. PLoS Genet 9:e1003429. https://doi.org/10.1371/journal.pgen.1003429

56. The COPERNIC project investigators, Granzotto A, Benadjaoud MA, Vogin G, Devic C, Ferlazzo ML et al (2016) Influence of nucleoshuttling of the ATM protein in the healthy tissues response to radiation therapy: toward a molecular classification of human radiosensitivity. Int J Radiat Oncol Biol Phys 94:450-460. https ://doi.org/10.1016/j.ijrobp.2015.11.013

57. van der Zee J, Gijselinck I, Dillen L, Van Langenhove T, Theuns J, Engelborghs S et al (2013) A pan-European study of the C9orf72 repeat associated with FTLD: geographic prevalence, genomic instability, and intermediate repeats. Hum Mutat 34:363-373. https://doi.org/10.1002/humu.22244

58. Walker C, Herranz-Martin S, Karyka E, Liao C, Lewis K, Elsayed W et al (2017) C9orf72 expansion disrupts ATM-mediated chromosomal break repair. Nat Neurosci. https://doi.org/10.1038/ nn. 4604

59. Wei Y (2014) Characterization of hnRNP A3 isoforms in the A2RE-proteome. School of Chemistry and Molecular Biosciences, The University of Queensland, City

60. Wen X, Tan W, Westergard T, Krishnamurthy K, Markandaiah SS, Shi Y et al (2014) Antisense proline-arginine RAN dipeptides linked to C9ORF72-ALS/FTD form toxic nuclear aggregates that initiate in vitro and in vivo neuronal death. Neuron 84:1213-1225. https://doi.org/10.1016/j.neuron.2014.12.010

61. West SC (2003) Molecular views of recombination proteins and their control. Nat Rev Mol Cell Biol 4:435-445. https://doi. org/10.1038/nrm1127

62. White MR, Mitrea DM, Zhang P, Stanley CB, Cassidy DE, Nourse A et al (2019) C9orf72 Poly(PR) dipeptide repeats disturb biomolecular phase separation and disrupt nucleolar function. Mol Cell. https://doi.org/10.1016/j.molcel.2019.03.019

63. Zamiri B, Reddy K, Macgregor RB Jr, Pearson CE (2014) TMPyP4 porphyrin distorts RNA G-quadruplex structures of the disease-associated $\mathrm{r}(\mathrm{GGGGCC}) \mathrm{n}$ repeat of the $\mathrm{C} 9$ orf72 gene and blocks interaction of RNA-binding proteins. J Biol Chem 289:4653-4659. https://doi.org/10.1074/jbc.C113.502336

64. Zhang J, Perry G, Smith MA, Robertson D, Olson SJ, Graham DG et al (1999) Parkinson's disease is associated with oxidative damage to cytoplasmic DNA and RNA in substantia nigra neurons. Am J Pathol 154:1423-1429. https://doi.org/10.1016/s0002 -9440(10)65396-5

65. Zhang K, Donnelly CJ, Haeusler AR, Grima JC, Machamer JB, Steinwald $\mathrm{P}$ et al (2015) The C9orf72 repeat expansion disrupts nucleocytoplasmic transport. Nature 525:56-61. https://doi. org/10.1038/nature14973

66. Zhang YJ, Gendron TF, Grima JC, Sasaguri H, Jansen-West K, $\mathrm{Xu}$ YF et al (2016) C9ORF72 poly(GA) aggregates sequester and impair HR23 and nucleocytoplasmic transport proteins. Nat Neurosci 19:668-677. https://doi.org/10.1038/nn.4272

Publisher's Note Springer Nature remains neutral with regard to jurisdictional claims in published maps and institutional affiliations. 


\section{Affiliations}

\section{Yoshihiro Nihei ${ }^{1} \cdot$ Kohji Mori ${ }^{2} \cdot$ Georg Werner $^{3} \cdot$ Thomas Arzberger $^{1,4,5}$ - Qihui Zhou ${ }^{1}$ Barham Khosravi ${ }^{1}$.

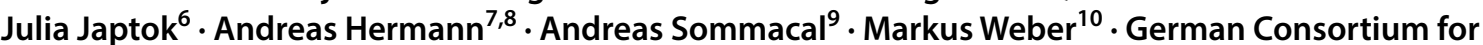 Frontotemporal Lobar Degeneration - Bavarian Brain Banking Alliance · Frits Kamp ${ }^{3} \cdot$ Brigitte Nuscher $^{3}$. Dieter Edbauer $^{1,11}$. Christian Haass ${ }^{1,3,11}$}

Yoshihiro Nihei

Yoshihiro.Nihei@dzne.de

Kohji Mori

kmori@psy.med.osaka-u.ac.jp

Georg Werner

Georg.Werner@mail03.med.uni-muenchen.de

Thomas Arzberger

Thomas.Arzberger@med.uni-muenchen.de

Qihui Zhou

Qihui.Zhou@dzne.de

Barham Khosravi

Bahram.Khosravi@dzne.de

Julia Japtok

julia.japtok@uniklinikum-dresden.de

Andreas Hermann

Andreas.Hermann@med.uni-rostock.de

Andreas Sommacal

andreas.sommacal@kssg.ch

Markus Weber

markus.weber@kssg.ch

Frits Kamp

frits.kamp@mail03.med.uni-muenchen.de

Brigitte Nuscher

brigitte.nuscher@mail03.med.uni-muenchen.de

Dieter Edbauer

dieter.edbauer@dzne.de

1 German Center for Neurodegenerative Diseases (DZNE) Munich, 81377 Munich, Germany
2 Department of Psychiatry, Osaka University Graduate School of Medicine, Yamadaoka 2-2 D3, Suita 565-0871, Osaka, Japan

3 Metabolic Biochemistry, Biomedical Center (BMC), Faculty of Medicine, Ludwig-Maximilians-Universität München, 81377 Munich, Germany

4 Center for Neuropathology and Prion Research, Ludwig-Maximilians-Universität München, 81377 Munich, Germany

5 Department of Psychiatry and Psychotherapy, Ludwig-Maximilians Universität München, 80336 Munich, Germany

6 Department of Neurology, Technische Universität Dresden, 01307 Dresden, Germany

7 Translational Neurodegeneration Section "Albrecht-Kossel", Department of Neurology and Center for Transdisciplinary Neurosciences Rostock (CTNR), University Medical Center Rostock, University of Rostock, 18147 Rostock, Germany

8 German Center for Neurodegenerative Diseases (DZNE) Rostock/Greifswald, 18147 Rostock, Germany

9 Institute for Pathology, Kanstonsspital St. Gallen, Rorschacher Strasse 95, 9007 St. Gallen, Switzerland

10 Muskelzentrum/ALS Clinic, Kantonsspital St. Gallen, Rorschacher Strasse 95, 9007 St. Gallen, Switzerland

11 Munich Cluster for System Neurology (SyNergy), 81377 Munich, Germany 